\title{
Electrical and mechanical analysis of a segmented solar thermoelectric generator under non-uniform heat flux
}

(i) The corrections made in this section will be reviewed and approved by a journal production editor.

Samson Shittu Writing - review \& editing Writing - original draft Validation Software Conceptualization ${ }^{\text {a }}$

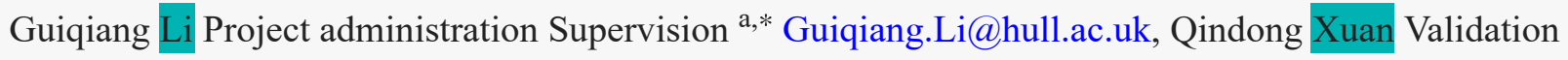

Software $^{\mathrm{b}}$, Xudong Zhao Funding acquisition ${ }^{\mathrm{a}, * *}$ Xudong.Zhao@hull.ac.uk, Xiaoli Ma Supervision ${ }^{\mathrm{a}}$, Yu Cui Visualization ${ }^{\text {a }}$

${ }^{a}$ Centre for Sustainable Energy Technologies, University of Hull, HU6 7RX, UK

${ }^{\mathbf{b}}$ Department of Thermal Science and Energy Engineering, University of Science and Technology of China, 96 Jinzhai Road, Hefei City, 230026, China

${ }^{*}$ Corresponding author.

${ }^{* *}$ Corresponding author.

\section{Abstract}

Optimization of segmented solar thermoelectric generator for power output enhancement has been well researched however, the mechanical reliability study of such devices is usually neglected. In addition, assumed heat flux distribution or uniform flux distribution from solar concentrators is usually used for solar thermoelectric generator however, this is not accurate. Therefore, this study presents a detailed three-dimensional numerical investigation on the effect of non-uniform and uniform heat flux on the electrical and mechanical performance of segmented and non-segmented solar thermoelectric generator. Flux distribution from a compound parabolic concentrator is obtained by ray tracing using Lighttools software and COMSOL 5.4 Multiphysics software is used to perform the numerical study based on finite element method. Thermal stress analysis in a fullscale solar thermoelectric generator is presented and the effects of load resistance, solar radiation and cold side temperature on performance of solar thermoelectric generator is analysed. Results show that the power output of the segmented solar thermoelectric generators in Case 3, Case 4 and Case 5 increased by $44.07 \%, 59.12 \%$ and $37.9 \%$ respectively compared to that of Case 1 (bismuth 
telluride non-segmented solar TEG) at $13000 \mathrm{~W} / \mathrm{m}^{2}$. Results from this study will provide valuable guidance for segmented and non-segmented solar thermoelectric generator design.

Keywords: Segmented thermoelectric generator; Non-uniform heat flux; Thermal stress; Finite element method; TEG

\section{Introduction}

Reduction in global carbon emission is needed urgently due to the reality of climate change and resulting negative impacts on the environment $[1,2]$. In addition, global demand for electricity is increasing rapidly while conventional electricity generation sources are diminishing speedily [3,4]. Therefore, research on development of clean electricity generation technologies as experienced a significant increase. Solar energy is a free, reliable and inexhaustible clean energy source capable of providing electricity therefore, it is regarded as one of the most promising solutions for clean electricity generation, fossil fuel consumption reduction and improved environmental conditions [5,6]. Large quantities of energy are usually discharged directly into the environment as waste heat from different sources such as automobiles, industrial processes, body etc. [7]. Therefore, waste heat recovery is very important as it can save a substantial amount of energy and reduce emissions [8].

One of the most widely used waste heat recovery technologies is the thermoelectric generator (TEG) which has attracted more attention recently for use in applications with large amount of waste heat such as vehicles [9 ]. A thermoelectric generator is a solid state device which converts heat directly into electricity via the Seebeck effect at the presence of temperature gradient across its hot and cold ends [10]. Compared to the other waste heat recovery technologies, the thermoelectric generator is advantageous because it provides zero environmental pollution, solid-state operation, silent operation, maintenance free operation and high reliability [11]. However, the thermoelectric generator suffers from low conversion efficiency which has prevented its wide spread application [12]. Geometry and material optimization of thermoelectric generators have attracted a great interest recently due to performance enhancement obtained [13]. Different geometries and structure of a thermoelectric generator have been proposed and optimized including segmented thermoelectric generator [ 14-16], annular thermoelectric generator [17-19], asymmetrical thermoelectric generator [20-23] and cascaded thermoelectric generator [24-26]. Each of these geometries and structure provide certain advantages in addition to some disadvantages. However, the consensus is that, geometry optimization can enhance the power output and conversion efficiency of a thermoelectric generator [27].

In theory, the power output and efficiency of the thermoelectric generator can also be enhanced by increasing the temperature difference across its thermoelectric legs and this can be achieved by the use of solar concentrators and/or advanced cooling methods [28]. Kossyvakis et al. [29] presented a numerical study based on finite element method on a solar thermoelectric generator. The effect of thermal and optical concentration was studied and results revealed that optical concentration enabled the achievement of a maximum power output of 33.7W. Furthermore, Jung et al. [30] presented a wearable solar thermoelectric generator with high temperature difference created by the use of a local solar absorber and thermoelectric legs on a polyimide substrate. Results showed that a high temperature difference of $20.9^{\circ} \mathrm{C}$ was obtained in comparison to typical 
temperature difference values of $1.5-4.1^{\circ} \mathrm{C}$. Liu et al. [31] developed a numerical model for estimating the performance of a flat-plate solar thermoelectric generator and the influence of thermal concentration ratio, length of thermoelectric legs and other geometrical factors on the performance of the device were studied. Results showed that geometry optimization could significantly improve the performance of the solar thermoelectric generator. In addition, Lv et al. [32] presented an experimental and numerical study on a solar thermoelectric generator with heat pipe evacuated tubular collector, solar selective absorber (SSA) and thermoelectric modules. Experimental results revealed a peak electrical efficiency of $5.2 \%$ and peak exergy efficiency of $7.17 \%$.

A consequence of using solar concentrators to enhance the performance of a thermoelectric generator is the resultant non-uniform heat flux from the solar concentrators. Yin et al. [33] studied the effect of non-uniform illumination on the performance of a solar thermoelectric generator using a three-dimensional finite element model. Two-dimensional Gaussian distribution was used to model the illumination profiles incident on the TEG and results show that the non-uniform illumination greatly affected the temperature distribution and voltage distribution in the solar thermoelectric generator. Similarly, Admasu et al. investigated the effects of temperature non-uniformity over the heat spreader on the power output of a thermoelectric generator. The power output from a thermoelectric generator with uniform temperature distribution and that with non-uniform temperature over the heat spreader was compared and finite element method was used to perform the numerical study in addition to the experimental study carried out. Results showed that uniform temperature distribution over the heat spreader provides enhanced power output in comparison to the non-uniform temperature distribution. Furthermore, He et al. [34] performed an experimental and numerical study on a TEG. The impacts of non-uniform heat flux on the thermoelectric generators connected in series and/or in parallel were studied and results revealed that non-uniform heat flux mainly affects the power output of thermoelectric generators in parallel connection rather than series connection.

In recent years, research on segmented thermoelectric generator (STEG) has significantly increased because under ideal conditions, segmentation of different materials can enable the combination of a material with high efficiency at high temperature with a different material with high efficiency at low temperature [35]. Therefore, the overall performance of the STEG can be enhanced due to both materials operating at their most efficient temperature range [36]. Zhang et al. [37] presented a comprehensive method for optimizing the length ratio of a segmented thermoelectric generator. Constant surface temperature and constant heat transfer coefficient were utilized as the two different thermal boundary conditions and results showed that the optimum length ratio in a STEG is dependent on the thermoelectric materilas, heat transfer conditions and the geometry. Furthermore, Xiao et al. [38] presented a three-dimensional finite element model of a segmented thermoelectric generator with bismuth telluride and Skutterudite materials as the cold segment and hot segment thermoelectric materials respectively. Results revealed that the total conversion efficiency of the STEG with three-stage thermoelectric module was 10.52\%. Ouyang et al. [39] presented a three-dimensional finite element analysis of a segmented thermoelectric generator with cost in consideration. Results showed that the thermoelectric figure of merit is the most important parameter to be considered when choosing a thermoelectric material. Liu et al. [40] presented a new design of solar thermoelectric generator with segmented thermoelectric materials and asymmetrical legs. Results revealed that optimization of the leg length ratio increased the power output of the STEG by $14.9 \%$. Furthermore, Ma et al. [41] analysed the performance 
of an engine exhaust-based segmented thermoelectric generator and length ratio optimization was performed. Bismuth telluride $\left(\mathrm{Bi}_{2} \mathrm{Te}_{3}\right)$ and Skutterudite $\left(\mathrm{CoSb}_{3}\right)$ thermoelectric materials were used and results showed that the application of optimal segmented ratio in the STEG provided a power output enhancement of $6.8 \%$.

The operation of solar thermoelectric generators at high temperature causes development of thermal stress within the module. Consequently, it is important to study the thermal stress developed in thermoelectric generators as it provides valuable information on location of high stress in the modules and reliability of the module [42]. This information can be used to optimize the module and therefore, increase the life span of the modules. Fan et al. [43] presented a numerical study on the thermoelectric performance and mechanical reliability of a segmented annular thermoelectric generator under steady state and transient conditions. Threedimensional finite element method was used and results showed that the maximum von Mises stress in the hotsegment decreased by $12.5 \%$ compared with a single-Skutterudite annular thermoelectric generator. Ibeagwu [ 44] studied the effect of different leg geometries on the electrical and mechanical performance of a thermoelectric generator and results revealed that thermal stress can be reduced by geometry optimization. Similarly, Wu et al. [45] analysed the thermal stress developed in a thermoelectric generator with different module geometry configurations. Results showed that the use of tin soldering could significantly reduce the thermal stress intensity in the module and increase thermal efficiency. Furthermore, Jia et al. [46] estimated the mechanical performance of a segmented thermoelectric generator using a three-dimensional finite element model. Results showed that the consideration of elastoplastic deformation of copper strips and wielding strips could significantly reduce the thermal stress in the segmented thermoelectric generator.

The literature review above demonstrates the effectiveness and appropriateness of three-dimensional finite element method in optimizing segmented thermoelectric generators for electrical and mechanical improvements. In addition, the advantage of thermoelectric material segmentation has been shown. Furthermore, the review also shows the negative influence of non-uniform heat flux and thermal stress in a thermoelectric generator. However, most studies on solar thermoelectric generator assume uniform illumination from solar concentrators while the studies on non-uniform heat flux assume heat flux distributions using Gaussian distribution. In reality, solar concentrators do not provide uniform heat flux consequently, it is important to consider the actual flux distribution from a solar concentrator rather than an assumed flux distribution or uniform distribution. Therefore, for the first time, this study presents a detailed threedimensional numerical investigation of the effect of non-uniform heat flux from a compound parabolic concentrator (CPC) on the electrical and mechanical performance of a segmented thermoelectric generator. A comparison between non-uniform and uniform heat flux is presented and thermal stress analysis is performed. In addition, a full-scale thermoelectric generator is studied rather than an uni-couple as most previous studies have utilized. COMSOL 5.4 Multiphysics software is used to perform the numerical study while Lighttools software is used for the ray tracing simulation to obtain the heat flux distribution from the compound parabolic concentrator. Consequently, the main goal of this paper is to study the electrical performance of a segmented thermoelectric generator in addition to its mechanical reliability under uniform and non-uniform heat flux from a compound parabolic concentrator and using a full-scale thermoelectric generator whose geometry is optimized. The remainder of this paper is organized as follows: Section 2 presents the structure and material, Section 3 presents the numerical model and validation, Section 4 presents the results and subsequent discussion while Section 5 presents the conclusions. 


\section{Structure and material}

The schematic of the segmented thermoelectric generator and non-segmented thermoelectric generator analysed in this study is shown in Fig. 1a and b respectively. A commercial thermoelectric generator (GM25071-14-16) with 71 pairs of thermoelectric legs connected electrically in series and thermally in parallel is used in this study. The only difference between Fig. 1a and b is the presence of segmented p-type and n-type thermoelectric materials. However, the total length of the thermoelectric legs in both cases is kept constant throughout this study at a value of $2 \mathrm{~mm}$. As shown in Fig. 1b, the thermoelectric generator comprises of ceramic layers, copper layers, solder layers and thermoelectric legs (p-type and n-type). The ceramic layer material is Aluminium oxide, the solder layer material is tin-lead solder $(60 \mathrm{Sn}-40 \mathrm{~Pb})$ while two different thermoelectric materials are used in the STEG. Bismuth telluride is used as the cold segment (P1-type and N1type) thermoelectric material while Skutterudite is used as the hot segment (P2-type and N2-type) thermoelectric material. In addition, the temperature dependency of both thermoelectric material properties is considered as shown in Fig. 2. In both the segmented and non-segmented TEG, a solar selective absorber (SSA) is assumed to be present at the top of the ceramic. The ceramic enhances thermal conductivity, copper provides electrical connection and solder helps to alleviate the effect of thermal stress.

alt-text: Fig. 1

Fig. 1 


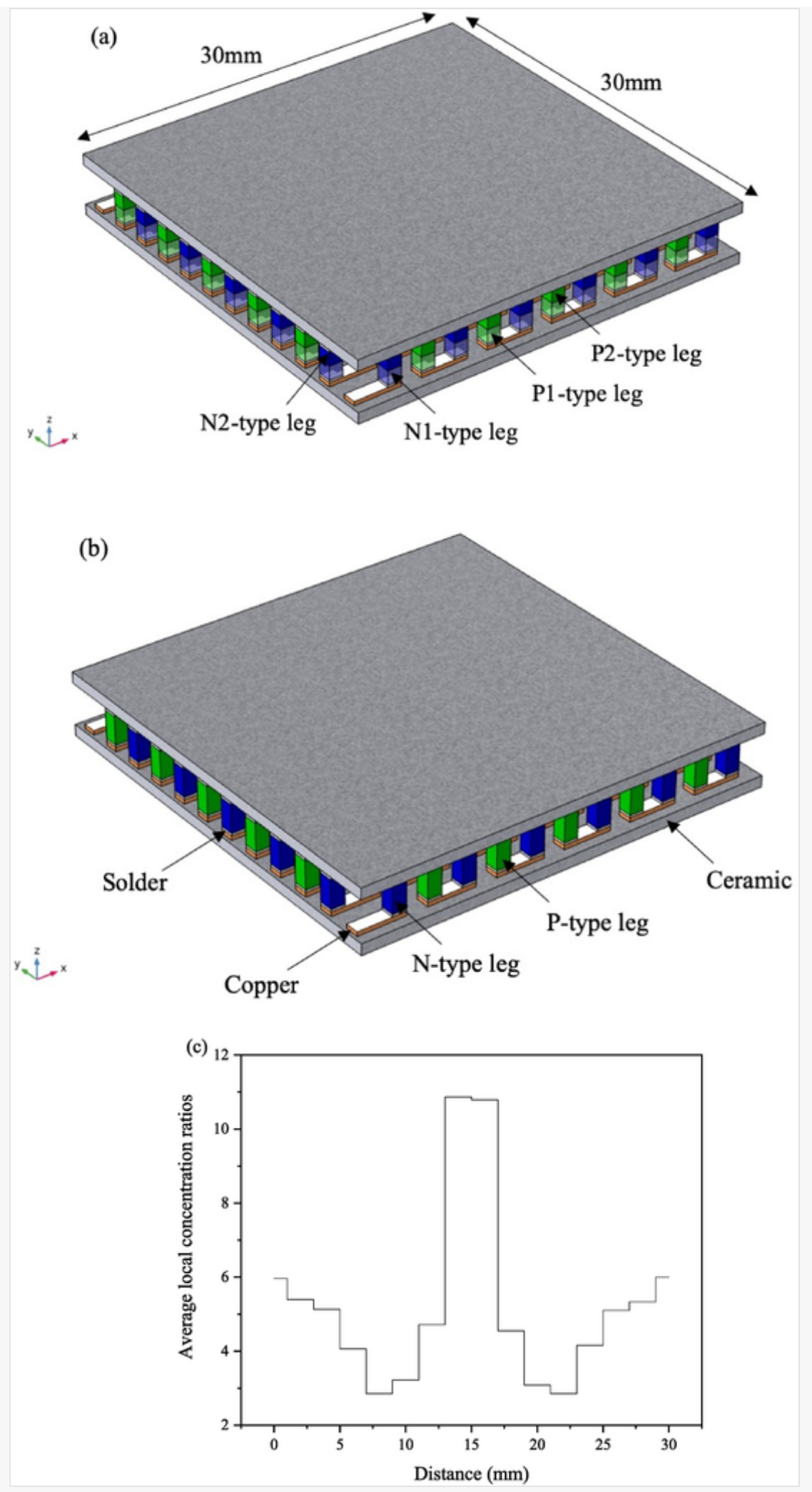

Schematic of (a) segmented thermoelectric generator (b) thermoelectric generator and (c) CPC flux distribution.

alt-text: Fig. 2

Fig. 2 

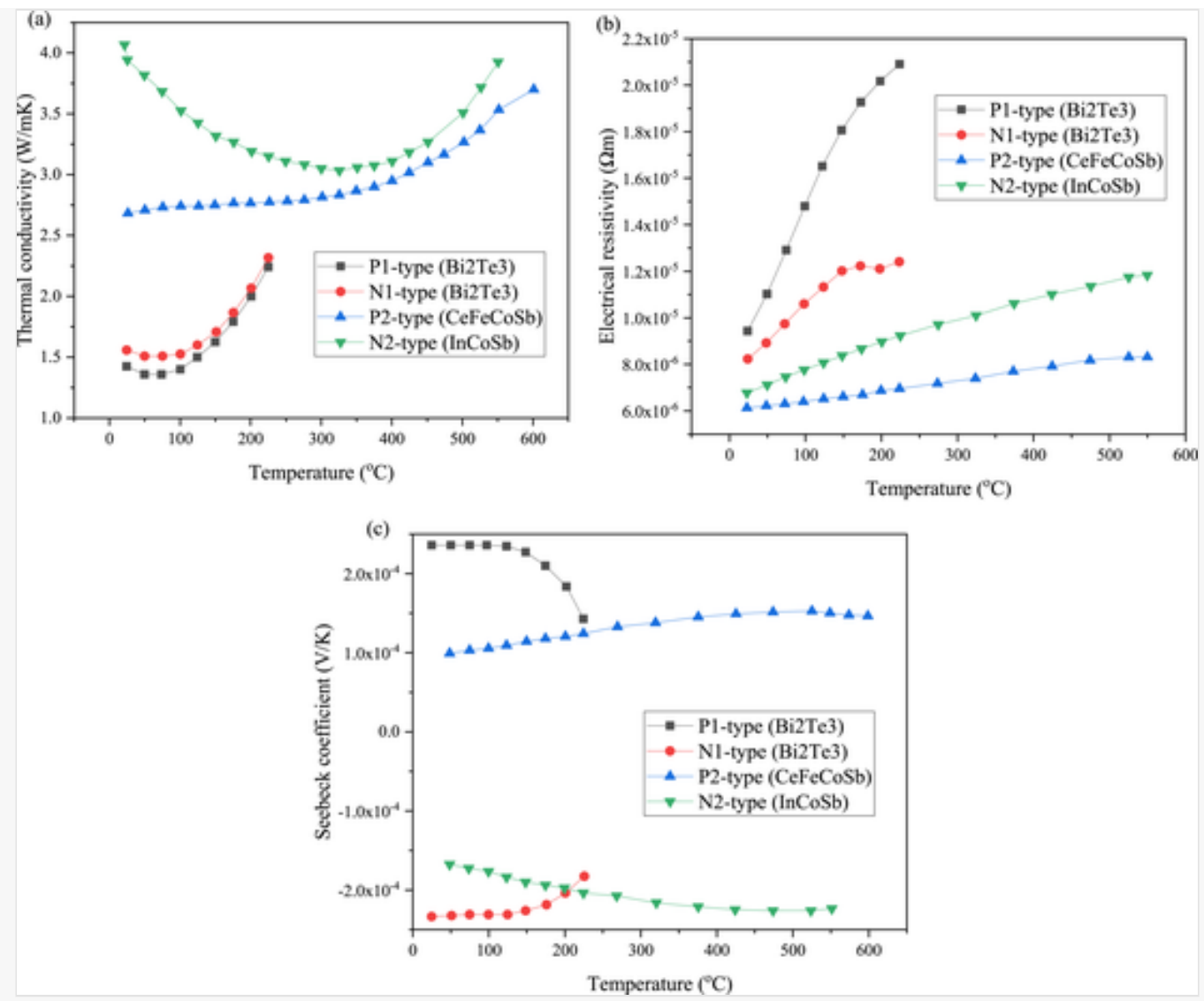

Temperature dependent thermoelectric material properties (a) thermal conductivity (b) electrical resistivity and (c) Seebeck coefficient [43].

In this study, the solar concentrator used is a compound parabolic concentrator (CPC) with a concentration ratio of 6. Firstly, SolidWorks is used to build the geometric model of the CPC before been transferred into Lighttools for the ray tracing simulation. For avoidance of repetition, details about the simulation parameters and the model for the CPC can be found in our published paper [47]. The flux distribution from the compound parabolic concentrator is shown in Fig. 1c. The geometric parameters used in this numerical study are listed in Table 1 while the remaining material properties utilized are listed in Table 2 . The emissivity and absorptivity of the SSA are 0.05 and 0.95 respectively. For the thermal stress analysis, copper and solder are considered as elastoplastic materials with yielding stress and tangential modulus of $70 \mathrm{MPa}, 24 \mathrm{GPa}$ and $26 \mathrm{MPa}, 8.9 \mathrm{GPa}$ respectively [18]. Furthermore, the tensile strength of the hot segment material (Skutterudite) is $142 \mathrm{MPa}$ [43] while the yielding stress of the cold segment material (Bismuth telluride) is $112 \mathrm{MPa}$ [48].

alt-text: Table 1

Table 1

(i) The table layout displayed in this section is not how it will appear in the final version. The representation below is solely purposed for providing corrections to the table. To preview the actual presentation of the table, please view the Proof. 
Geometric parameters $[33,42,51]$.

\begin{tabular}{|l|l|}
\hline Parameter & \multicolumn{1}{|c|}{ Value } \\
\hline Ceramic height & $0.8 \mathrm{~mm}$ \\
\hline Copper height & $0.3 \mathrm{~mm}$ \\
\hline Leg height & $1 \mathrm{~mm}$ \\
\hline Solder height & $0.175 \mathrm{~mm}$ \\
\hline Ceramic depth & $30 \mathrm{~mm}$ \\
\hline Ceramic width & $30 \mathrm{~mm}$ \\
\hline Leg width & $1 \mathrm{~mm}$ \\
\hline Leg depth & $1 \mathrm{~mm}$ \\
\hline
\end{tabular}

alt-text: Table 2

Table 2

(i) The table layout displayed in this section is not how it will appear in the final version. The representation below is solely purposed for providing corrections to the table. To preview the actual presentation of the table, please view the Proof.

Remaining material properties used in simulation $[43,54]$.

\begin{tabular}{|c|c|c|c|c|c|c|c|}
\hline & $\begin{array}{l}\text { Coefficient of } \\
\text { thermal } \\
\text { expansion, }\left(\frac{1}{K}\right)\end{array}$ & $\begin{array}{l}\text { Density, } \\
\rho_{d}\left(\frac{\mathrm{kg}}{\mathrm{m}^{3}}\right)\end{array}$ & $\begin{array}{l}\text { Specific heat } \\
\text { capacity, } \\
C_{p}\left(\frac{\mathrm{J}}{\mathrm{kg} \cdot \mathrm{K}}\right)\end{array}$ & $\begin{array}{l}\text { Young's } \\
\text { Modulus, E } \\
(G P a)\end{array}$ & $\begin{array}{l}\text { Poisson's } \\
\text { ratio }\end{array}$ & $\begin{array}{l}\text { Thermal } \\
\text { conductivity, } \\
\kappa\left(\frac{W}{m \cdot K}\right)\end{array}$ & $\begin{array}{l}\text { Electrical } \\
\text { conductivity, } \\
\sigma\left(\Omega^{-1} \cdot m^{-1}\right)\end{array}$ \\
\hline Ceramic & $0.68 \mathrm{e}-5$ & 3970 & 800 & 340 & 0.22 & 25 & $1 \mathrm{e}-12$ \\
\hline Solder & $2.7 e-5$ & 7240 & 210 & 44.5 & 0.33 & 55 & $2 \mathrm{e} 7$ \\
\hline Copper & $1.7 e-5$ & 8930 & 386 & 120 & 0.3 & 385 & $5.9 \mathrm{e} 7$ \\
\hline $\mathrm{Bi}_{2} \mathrm{Te}_{3}$ & $0.8 e-5-1.32 e-5$ & 7740 & 154.4 & $65-59$ & 0.23 & - & - \\
\hline Skutterudite & $0.8 \mathrm{e}-5$ & 6800 & 225 & 110 & 0.21 & - & - \\
\hline
\end{tabular}

\section{Numerical model and validation}

Coupled equations of heat transfer and current density continuity can be used to describe the thermoelectric effect as follows [49]:

Heat energy conversion: 


$$
\rho_{d} C_{p} \frac{\partial T}{\partial t}+\nabla \cdot q^{\prime \prime}=Q^{\prime}
$$

Electric current continuity:

$$
\nabla \cdot J=\frac{\partial \rho_{c}}{\partial t}
$$

where $\rho_{c}$ is charge density, $\rho_{d}$ is density, $C_{p}$ is specific heat capacity, $t$ is time, $q^{\prime \prime}$ is the input heat flux and $Q^{\prime}$ is Joule heating energy.

$$
Q^{\prime}=J \cdot E
$$

$$
q^{\prime \prime}=-k \nabla \mathrm{T}+P^{\prime} J
$$

where $J$ is the electric current flux and $P^{\prime}$ is the Peltier coefficient.

$$
P^{\prime}=S T
$$

$$
\mathrm{J}=-\sigma \nabla \mathrm{V}-\sigma \alpha \nabla \mathrm{T}
$$

where $k$ is thermal conductivity, $\alpha$ is the Seebeck coefficient, $\sigma$ is electrical conductivity and $\mathrm{V}$ is electric scalar potential.

Combination of Equations (3)-(6) results in,

$$
\rho_{d} C_{p} \frac{\partial T}{\partial t}+\nabla \cdot(-k \nabla \mathrm{T}+\alpha T(-\sigma \nabla \mathrm{V}-\sigma \alpha \nabla \mathrm{T}))=(-\sigma \nabla \mathrm{V}-\sigma \alpha \nabla \mathrm{T})(-\nabla \mathrm{V})
$$

$$
-\sigma\left(\nabla^{2} \mathrm{~V}+\alpha \nabla^{2} T\right)=\frac{\partial \rho_{c}}{\partial t}
$$


The equations above are valid for both steady state heating and transient heating however, for steady state heating,

$$
\frac{\partial \rho_{c}}{\partial t}=0
$$

The maximum power output of a TEG can be obtained when the TEG's internal resistance $\left(R_{\text {in }}\right)$ is equal to the attached external load resistance $\left(R_{L}\right)$ and it is given as,

$$
P_{\text {out }}=\left(\frac{\alpha \Delta \mathrm{T}}{R_{L}+R_{\text {in }}}\right)^{2} \times R_{L}
$$

where $\Delta \mathrm{T}$ is the temperature difference across the TEG.

$$
P_{\text {out }}=V_{L} I=R_{L} I^{2}
$$

where $V_{L}$ is load output voltage and $I$ is TEG current.

The efficiency of the thermoelectric generator is given as,

$$
\eta_{\text {teg }}=\frac{P_{\text {out }}}{Q_{\text {in }}}
$$

where $Q_{i n}$ is the input power.

\subsection{Solar thermoelectric generator}

The input power at the top surface of the solar thermoelectric generator is expressed as [46],

$$
Q_{\text {in }}=C G A_{s} \alpha_{s} \eta_{o p t}
$$

where $A_{s}$ is the solar selective above area $(30 \mathrm{~mm} \times 30 \mathrm{~mm}), \alpha_{s}$ is the absorptivity of the SSA, $\eta_{\text {opt }}$ is the optical efficiency (0.90) of the concentrator, $C$ is the CPC concentration ratio and $G$ is the solar radiation which is varied in this study. For the uniform heat flux, a concentration ratio of 6 is applied while for the nonuniform heat flux, the concentration ratio is obtained from Fig. 1c along the $\mathrm{x}$-axis. 
Heat loss due to radiation and convection at the top surface of the segmented and non-segmented solar TEG is considered in this study. The sky temperature is used for the radiative heat loss calculation and it is given as [ $28]$,

$$
T_{s k y}=T_{a}-6(K)
$$

where $T_{a}$ is the ambient temperature and $T_{s k y}$ is sky temperature.

Convective heat transfer coefficient is given in terms of wind speed as [28],

$$
h=5.82+4.07 v
$$

where $v$ is the wind speed $(1 \mathrm{~m} / \mathrm{s})$.

Lastly, the efficiency of the solar thermoelectric generator is given as [38]:

$$
\eta_{\text {solarteg }}=\eta_{\text {teg }} \alpha_{s} \eta_{\text {opt }}
$$

\subsection{Thermal stress equations}

The coupled thermal stress equations used to describe the displacement-strain relation are given as [50]:

$$
\bar{\varepsilon}_{x x}=\frac{\partial \bar{u}}{\partial \bar{x}}, \bar{\varepsilon}_{y y}=\frac{\partial \bar{v}}{\partial \bar{y}}, \bar{\varepsilon}_{z z}=\frac{\partial \bar{w}}{\partial \bar{z}}
$$

$$
\bar{\varepsilon}_{x y}=0.5\left(\frac{\partial \bar{u}}{\partial \bar{y}}+\frac{\partial \bar{v}}{\partial \bar{x}}\right), \bar{\varepsilon}_{y z}=0.5\left(\frac{\partial \bar{w}}{\partial \bar{y}}+\frac{\partial \bar{v}}{\partial \bar{z}}\right), \bar{\varepsilon}_{x z}=0.5\left(\frac{\partial \bar{w}}{\partial \bar{x}}+\frac{\partial \bar{u}}{\partial \bar{z}}\right)
$$

Using non-symmetrical Jacobian, the stress-strain relation can be expressed in dimensionless form as,

$$
\left\{\begin{array}{c}
\bar{\sigma}_{x x} \\
\bar{\sigma}_{y y} \\
\bar{\sigma}_{z z} \\
\bar{\sigma}_{y z} \\
\bar{\sigma}_{z x} \\
\bar{\sigma}_{x y}
\end{array}\right\}=\frac{\bar{E}}{(1+v)(1-2 v)}\left[\begin{array}{cccccc}
1-v & v & v & 0 & 0 & 0 \\
v & 1-v & v & 0 & 0 & 0 \\
v & v & 1-v & 0 & 0 & 0 \\
0 & 0 & 0 & 1-2 v & 0 & 0 \\
0 & 0 & 0 & 0 & 1-2 v & 0 \\
0 & 0 & 0 & 0 & 0 & 1-2 v
\end{array}\right] \times\left\{\begin{array}{c}
\bar{\varepsilon}_{x x} \\
\bar{\varepsilon}_{y y} \\
\bar{\varepsilon}_{z z} \\
\bar{\varepsilon}_{y z} \\
\bar{\varepsilon}_{z x} \\
\bar{\varepsilon}_{x y}
\end{array}\right\}-\left\{\begin{array}{c}
1 \\
1 \\
1 \\
0 \\
0 \\
0
\end{array}\right\} \overline{1-2 v}
$$


In a thermoelectric generator, the three-principal stress present are presented as $\sigma_{1}, \sigma_{2}$ and $\sigma_{3}$. Using the fourth strength theory of material mechanics, the von Mises equivalent stress can be obtained as,

$$
\sigma=\sqrt{\frac{\left[\left(\sigma_{1}-\sigma_{2}\right)^{2}+\left(\sigma_{2}-\sigma_{3}\right)^{2}+\left(\sigma_{3}-\sigma_{1}\right)^{2}\right]}{2}}
$$

The equations above are solved using finite element method and COMSOL 5.4 Multiphysics software to obtain the electrical and mechanical performance of the segmented and non-segmented solar thermoelectric generators.

\subsection{Boundary conditions}

The three-dimensional numerical model used in this study is simplified using the following assumptions.

1) Steady state conditions are assumed throughout the study.

2) Lower copper electrodes on the n-type and p-type legs are connected to an external load resistance.

3) Electrical and thermal contact resistance are ignored.

4) A fixed constraint is assumed at the hot side of the segmented and non-segmented solar thermoelectric generator.

5) Adiabatic condition is assumed on all side surfaces.

6) Constant temperature of $25^{\circ} \mathrm{C}$ is assumed at the cold side of the TEG unless otherwise stated.

\subsection{Model validation}

Grid independency validation is performed using four different mesh quantities including 26,942, 46,192, 77,131 and 144,107 named grid 1-4 respectively. The power output and temperature difference obtained from the grids are $0.9984 \mathrm{~W}, 0.9918 \mathrm{~W}, 0.9923 \mathrm{~W}, 0.9923 \mathrm{~W}$ and $114.693{ }^{\circ} \mathrm{C}, 114.311{ }^{\circ} \mathrm{C}, 114.342{ }^{\circ} \mathrm{C}, 114.342{ }^{\circ} \mathrm{C}$. Therefore, since the results converge, grid 4 is used throughout this study. Furthermore, the thermoelectric generator model is validated using manufacturer data [51] as seen in the datasheet for the TEG used (GM25071-14-16) as shown in Fig. 3a. In addition, the thermal stress model used in this study is validated with results from a previous study [52] as shown in Fig. 3b. Simulations conditions are reset to those in the referenced paper for proper comparison. It is clear from Fig. 3a and b that the results are in good agreement therefore, the numerical model presented in this study is both reliable and accurate. 

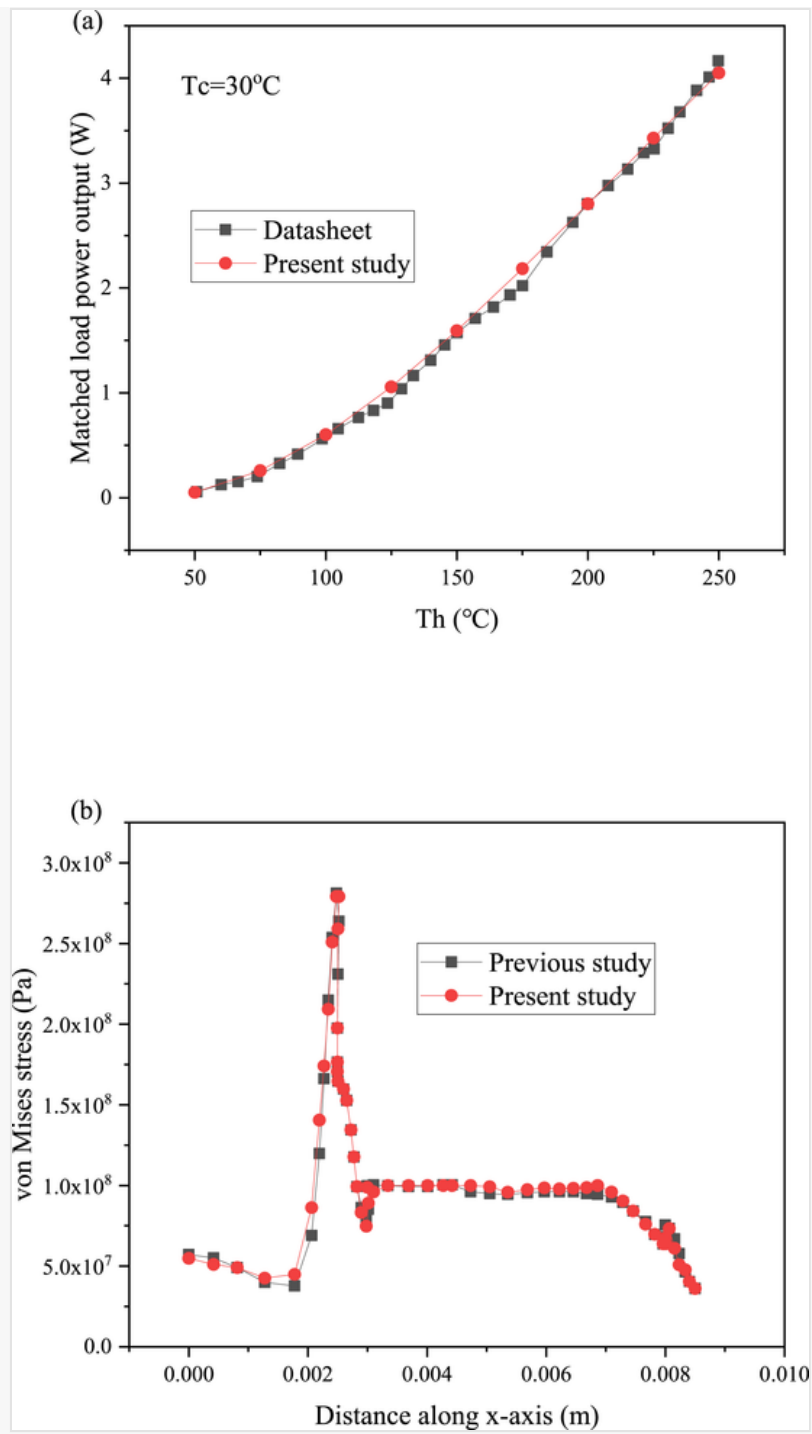

Validation of thermoelectric generator (a) power output with [51] and (b) thermal stress with [52].

\section{Results and discussion}

In this study, five different design cases for the segmented and non-segmented solar thermoelectric generator shown in Table 3 are analysed. As shown in Table 3, Case 1 and Case 2 corresponds to non-segmented solar thermoelectric generators with single material while Case 3, Case 4 and Case 5 correspond to the segmented solar thermoelectric generators with two different materials. It is important to note that the total thermoelectric length for the different cases is kept constant $(2 \mathrm{~mm})$ throughout this study and only the length ratio is optimized. The electrical and mechanical performance of the different design cases are analysed and results are presented in this section.

alt-text: Table 3

Table 3

i The table layout displayed in this section is not how it will appear in the final version. The representation below is 
solely purposed for providing corrections to the table. To preview the actual presentation of the table, please view the Proof.

Material proportions in different design cases.

\begin{tabular}{|c|c|c|c|c|c|}
\hline Material & Case 1 & Case 2 & Case 3 & Case 4 & Case 5 \\
\hline $\mathrm{Bi}_{2} \mathrm{Te}_{3}(\mathrm{P} 1 / \mathrm{N} 1)$ & $100 \%$ & 0 & $75 \%$ & $50 \%$ & $25 \%$ \\
\hline Skutterudite (P2/N2) & 0 & $100 \%$ & $25 \%$ & $50 \%$ & $75 \%$ \\
\hline
\end{tabular}

\subsection{Effect of external load resistance}

The maximum power output of the segmented and non-segmented solar thermoelectric generator is obtained by varying the attached external load resistance until it is equal to the internal resistance of the thermoelectric generator. Consequently, maximum power output can be obtained at an optimum load resistance. The effect of the load resistance on the power output and temperature difference across the legs of the thermoelectric generator for different design case is shown in Fig. 4. The effect of load resistance is analysed for the nonuniform heat flux at a solar radiation value of $5000 \mathrm{~W} / \mathrm{m}^{2}$. As seen in Fig. 4a, the optimum load resistance for obtaining maximum power output is different for the cases considered. It can be seen that the optimum load resistance for Case 1 to Case 5 is $6 \Omega, 3 \Omega, 5 \Omega, 4 \Omega$ and $4 \Omega$ respectively. In addition, it can be seen from Fig. 4a that Case 1 provides the highest power output next to Case 3. The reason for this is that, bismuth telluride is the best performing thermoelectric material at low temperature range thus, in Case 1; the percentage of bismuth telluride material is highest (100\%) next to Case $3(75 \%)$. At a higher temperature range, the results will be different and the significance of segmentation will become more obvious. The results in Fig. 4a can be better explained by the temperature results shown in Fig. 4b. As explained earlier, the power output of the thermoelectric generator is directly related to the temperature difference across its thermoelectric legs. As seen in Fig. 4b, Case 1 as the highest temperature difference across the legs consequently, its power output is the highest. In addition, it can be seen from Fig. 4b, that increase in load resistance leads to an increase in temperature difference due to the additional resistivity heating. Furthermore, Fig. $4 \mathrm{~b}$ shows an increase in temperature difference as the load resistance is increased and this is because the transfer of heat in thermoelectric generators is influenced by the heat conduction and Peltier effect of the thermoelectric legs. Therefore, as the load resistance is increased, the thermoelectric current decreases and the quantity of heat transferred across the thermoelectric legs is reduced thus, temperature difference is increased. This finding is in agreement with previous finding of Yin et al. [53]. Consequently, the optimum load resistance values for the different cases shown in Fig. 4 are used for the remainder of this study.

alt-text: Fig. 4

Fig. 4 

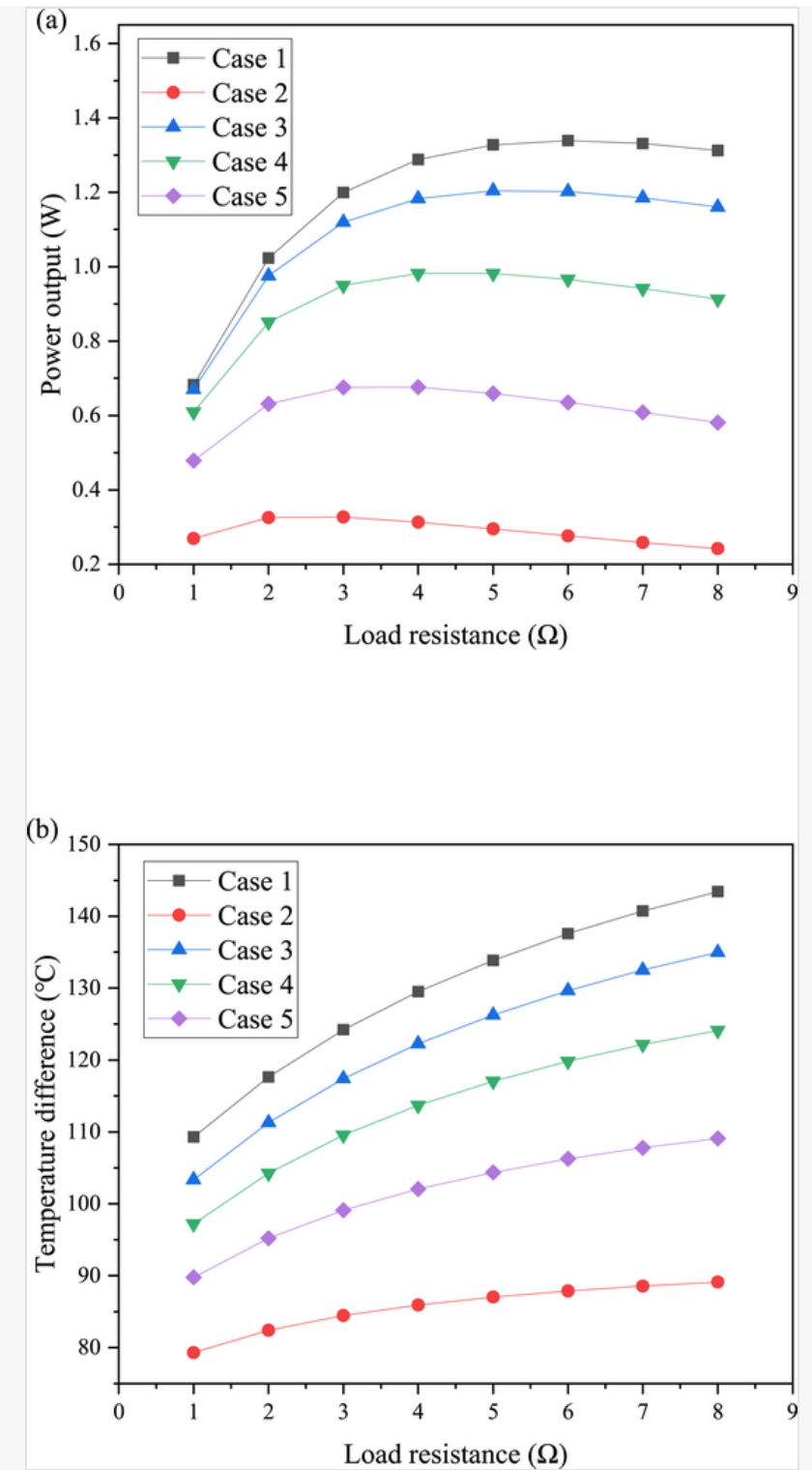

Variation of load resistance with (a) power output and (b) temperature difference.

\subsection{Effect of solar radiation}

Variation of solar radiation affects the amount of input energy absorbed by the thermoelectric generator and consequently its power output and efficiency. For the different cases, Fig. 5a shows the effect of solar radiation variation on the power output of the solar thermoelectric generator under non-uniform heat flux. As expected, the power output for most case increase as the solar radiation increase due to the increase in temperature difference across the module. However, for Case 1 and Case 3 in which the percentage of bismuth telluride material proportion is high $(100 \%$ and $75 \%$ respectively), it can be seen that the power output shows a decreasing trend after an initial increase. This is because; bismuth telluride material is a low temperature range $\left(<200{ }^{\circ} \mathrm{C}\right)$ thermoelectric material therefore, once the operating temperature is exceeded, it becomes less efficient and its power output decreases. Contrarily, Skutterudite material is a medium temperature range $\left(<500{ }^{\circ} \mathrm{C}\right)$ therefore, the power output in Case 2 and Case 5 where the Skutterudite material proportion is high ( $100 \%$ and $75 \%$ respectively) increases linearly as solar radiation increases. This finding is in agreement with 
previous finding of $\mathrm{Ma}$ et al. [41]. Consequently, it is important to consider the operating temperature range before choosing an appropriate thermoelectric material. Furthermore, it can be seen from Fig. 5a that the solar radiation, which influences the operating temperature, determines the most appropriate design case for the solar thermoelectric generator. For example, when the solar radiation was between $11000 \mathrm{~W} / \mathrm{m}^{2}$ to $17000 \mathrm{~W} / \mathrm{m}^{2}$, Case 4 provides the highest power output, which also increases from $3.81 \mathrm{~W}$ to $7.01 \mathrm{~W}$ at that range. However, at a solar radiation value greater than $17000 \mathrm{~W} / \mathrm{m}^{2}$, it can be seen that Case 5 provides the highest power output. This is because, at such high radiation value, the operating temperature of the module will be high consequently; Case 5, which has a high proportion of Skutterudite, provides the highest power output.

alt-text: Fig. 5

\section{Fig. 5}
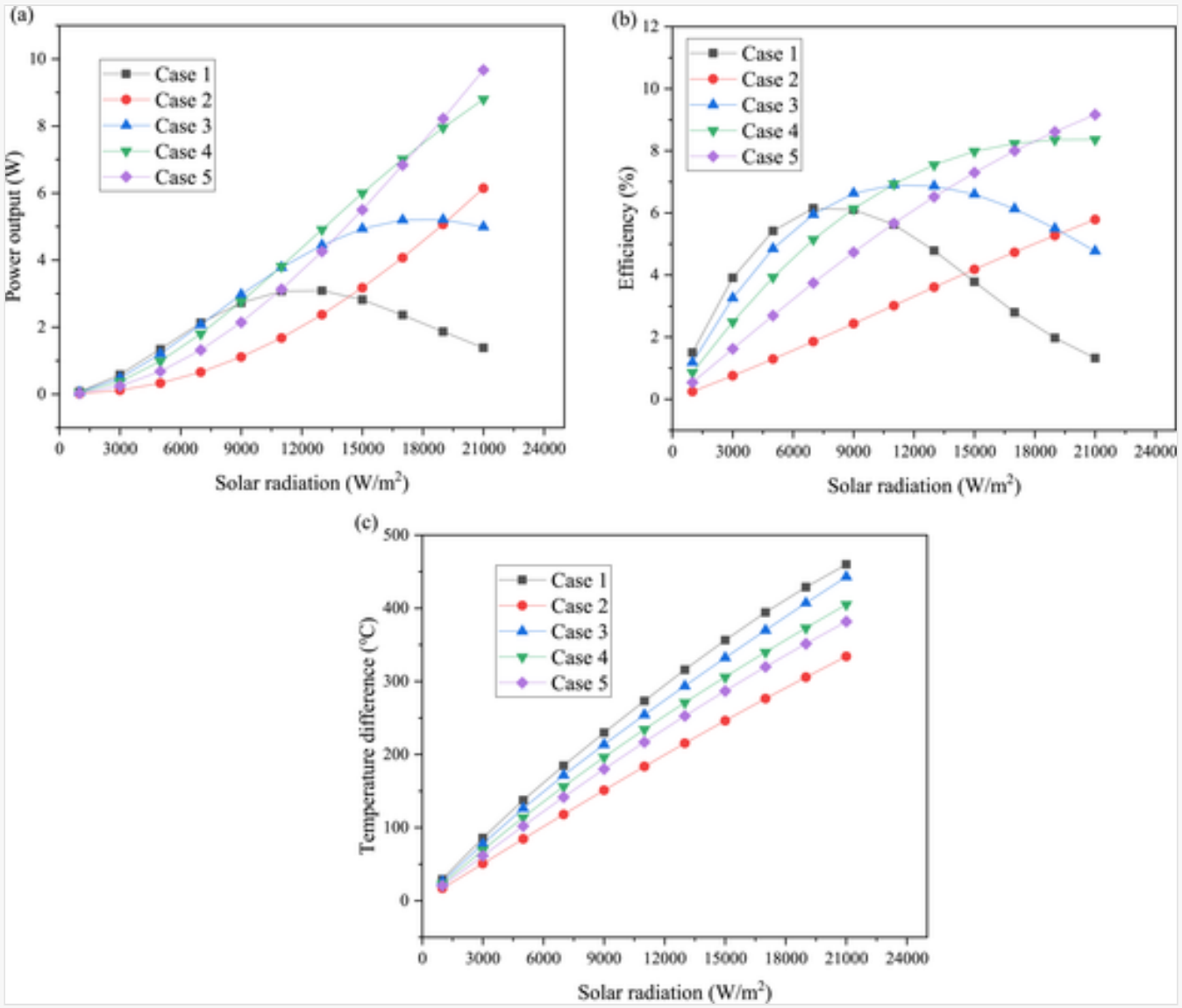

Effect of solar radiation on (a) power output (b) efficiency (c) temperature difference.

The significance of segmentation can also be seen from Fig. 5a in terms of power output. Comparing the highest power output obtained from Case 1 (bismuth telluride non-segmented solar TEG) which is 3.09W at $13000 \mathrm{~W} / \mathrm{m}^{2}$, to the power output of the segmented thermoelectric generator (Case 3, Case 4 and Case 5). It can be seen that the power output of Case 3, Case 4 and Case 5 increased by $44.07 \%, 59.12 \%$ and $37.9 \%$ respectively compared to that of Case 1 at $13000 \mathrm{~W} / \mathrm{m}^{2}$. Similarly, comparing the highest power output obtained from Case 5 (Skutterudite non-segmented solar TEG) which is $6.15 \mathrm{~W}$ at $21000 \mathrm{~W} / \mathrm{m}^{2}$, to that from 
the segmented cases. It can be seen that the power output of Case 4 and Case 5 increased by $43.18 \%$ and $57.4 \%$ respectively compared to that of Case 5 at $21000 \mathrm{~W} / \mathrm{m}^{2}$ while that of Case 3 decreased by $18.76 \%$ because of the higher proportion of bismuth telluride material. As expected, Fig. $5 \mathrm{~b}$ shows that Case 1 provides the highest efficiency at low temperature range corresponding to solar radiation values of $1000 \mathrm{~W} / \mathrm{m}^{2}$ to $7000 \mathrm{~W} / \mathrm{m}^{2}$. However, the advantage of the segmented design becomes more obvious at high radiation values. In addition, the trends observed in Fig. 5a and b are similar consequently, operating temperature is a critical parameter to be considered in designing highly efficient solar thermoelectric generators. Furthermore, Fig. 5c shows that the temperature difference across the thermoelectric legs increase as the solar radiation increases. This is an expected phenomenon since the cold side temperature is maintained at a fixed value. In addition, Fig. 5c (just like Fig. 4b) shows that Case 1 provides the highest temperature difference because it is made up of $100 \%$ bismuth telluride material, which has low thermal conductivity (as shown in Fig. 2a) that helps maintain the temperature gradient between the hot and cold side. Generally, thermoelectric materials with high electrical conductivity, low thermal conductivity and high Seebeck coefficient are desirable.

A comparison between the performance of the solar thermoelectric generators under non-uniform and uniform heat flux at different solar radiation values is shown in Fig. 6. The trends for both non-uniform and uniform heat flux are similar however, a slight difference still exists. It can be seen from Fig. 6a that the power output under uniform heat flux is higher than that under non-uniform heat flux however, after a saturation point is reached, the module under uniform heat flux suffers a more steep decrease in power output compared to that under non-uniform heat flux. This is because, under uniform heat flux, a higher amount of solar energy is absorbed by the solar TEG compared to that under non-uniform heat flux. Consequently, once the optimum operating temperature for bismuth telluride is exceeded, the power output under uniform heat flux decreases faster than that under non-uniform heat flux because of its higher operating temperature. However, at a solar radiation value of $11000 \mathrm{~W} / \mathrm{m}^{2}$, the power output of Case 1 under uniform heat flux increased by $1.53 \%$ compared to that under non-uniform heat flux. Furthermore, Fig. $6 \mathrm{~b}$ shows that the power output of Case 2 increases as solar radiation increases under both non-uniform and uniform heat flux. In fact, the significance of uniformity becomes very clear at higher radiation values. For example, at a radiation value of $11000 \mathrm{~W} / \mathrm{m}^{2}$, the power output of Case 2 under uniform heat flux increased by $31.81 \%$ compared to that under non-uniform heat flux. At the same radiation value of $11000 \mathrm{~W} / \mathrm{m}^{2}$, the power output of Case 3,4 and 5 under uniform heat flux increased by $14.05 \%, 22.47 \%$ and $27.81 \%$ respectively, compared to that under non-uniform heat flux. Consequently, uniform heat flux is beneficial for enhanced power output. Furthermore, the results in Fig. 6 can be better explained by the temperature results shown in Fig. 7a-c, as there is a direct correlation between power output of a solar thermoelectric generator and the temperature difference across its thermoelectric legs.

alt-text: Fig. 6

Fig. 6 

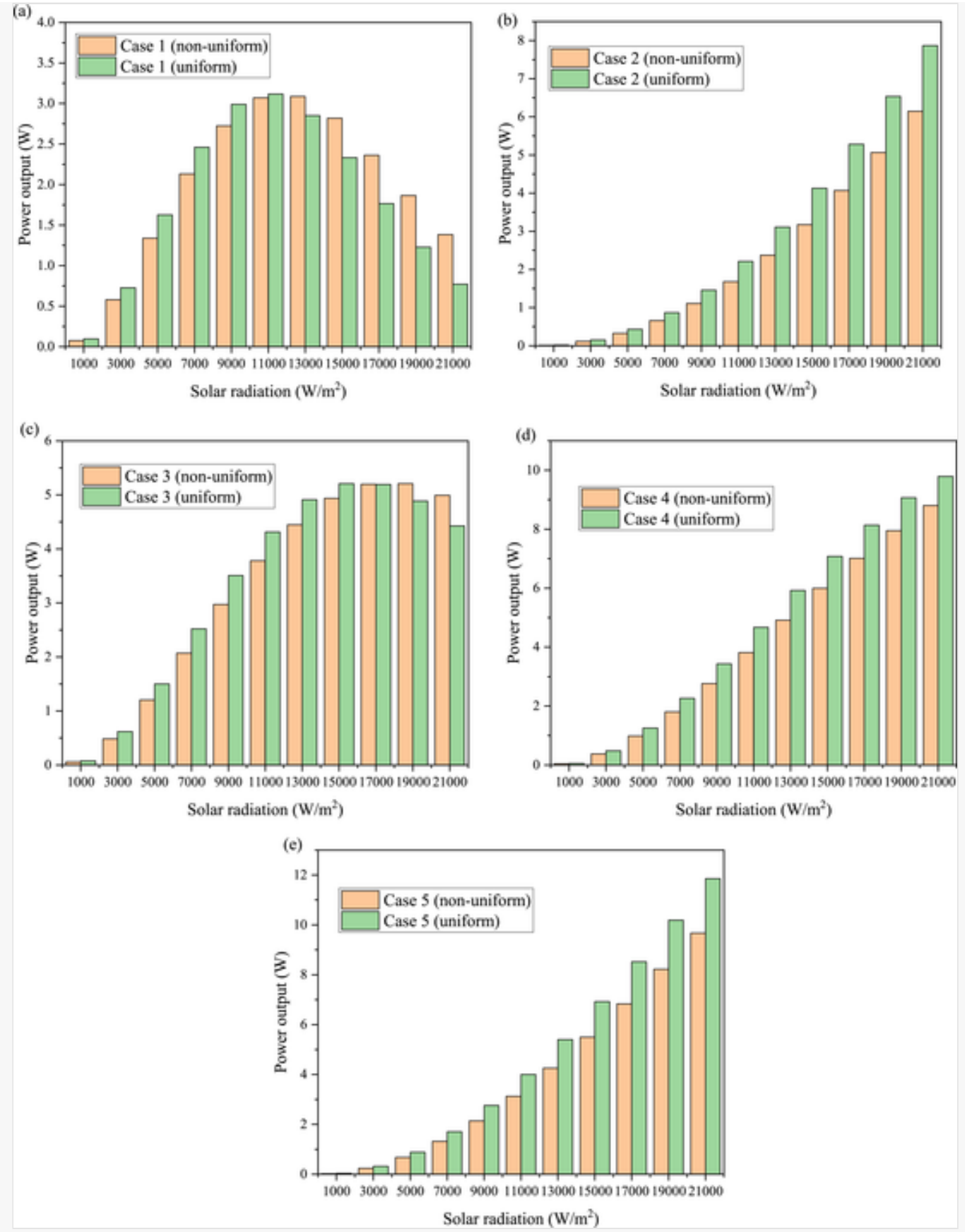

Comparison of non-uniform and uniform heat flux power output for (a) Case 1 (b) Case 2 (c) Case 3 (d) Case 4 and (e) Case 5.

alt-text: Fig. 7

Fig. 7 

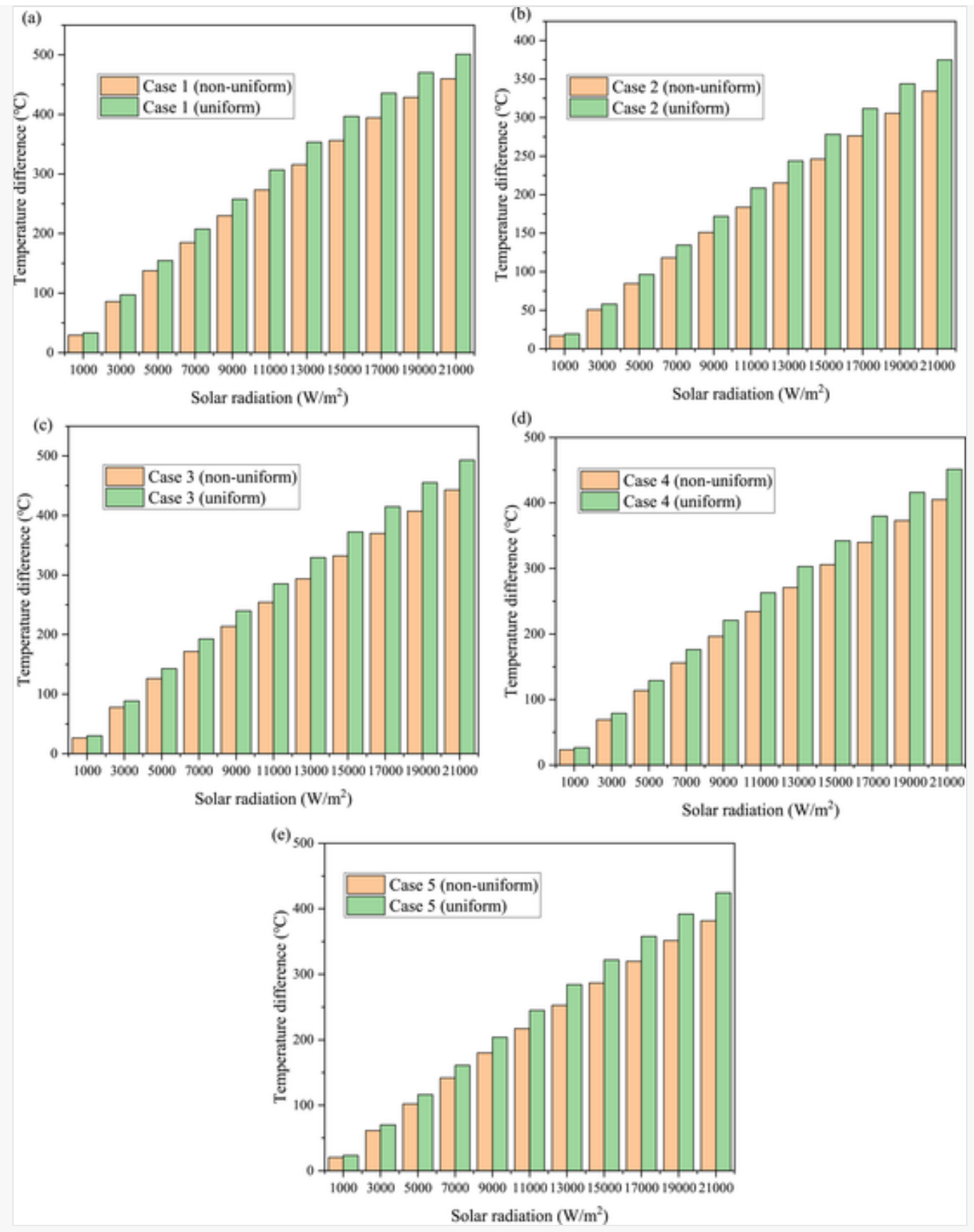

Comparison of non-uniform and uniform heat flux temperature difference for (a) Case 1 (b) Case 2 (c) Case 3 (d) Case 4 and (e) Case 5.

\subsection{Effect of cold side temperature}

Apart from the solar radiation, the cold side temperature of the solar thermoelectric generator significantly affects its power output and conversion efficiency as shown in Fig. 8. At a constant solar radiation value of $5000 \mathrm{~W} / \mathrm{m}^{2}$, the cold side temperature is varied and the resulting power output of the different design cases is shown in Fig. 8a for the non-uniform heat flux. It can be seen that the power output decreases as the cold side temperature increases for the different cases because of the decrease in temperature difference. For example, the power output of Case 1, Case 3, Case 4 and Case 5 all decrease by $19.66 \%, 16.54 \%, 12.61 \%$ and $5.65 \%$ respectively as the cold side temperature increases from $20^{\circ} \mathrm{C}$ to $55^{\circ} \mathrm{C}$. Similarly, as shown in Fig. $5 \mathrm{~b}$, the 
efficiency of Case 1, Case 3, Case 4 and Case 5 all decrease by $18.58 \%, 15.36 \%, 11.34 \%$ and $4.23 \%$ respectively as the cold side temperature increases from $20{ }^{\circ} \mathrm{C}$ to $55{ }^{\circ} \mathrm{C}$. Furthermore, Fig. $5 \mathrm{c}$ shows the decrease in temperature difference across the thermoelectric legs as the cold side temperature increases for the different cases. This is expected as the increase in cold side temperature prevents effective cooling of the solar thermoelectric generator and consequently, reduces its temperature gradient. Therefore, effective cooling of thermoelectric generators is essential for performance enhancement. It can also be seen from Fig. 8 that the effect of cold side temperature variation on performance of Case 2 is not very significant. This is because the hot side of the solar TEG is subjected to a heat flux rather than a constant temperature consequently, as the cold side temperature is varied, the hot side temperature also varies.

alt-text: Fig. 8

\section{Fig. 8}

(a)

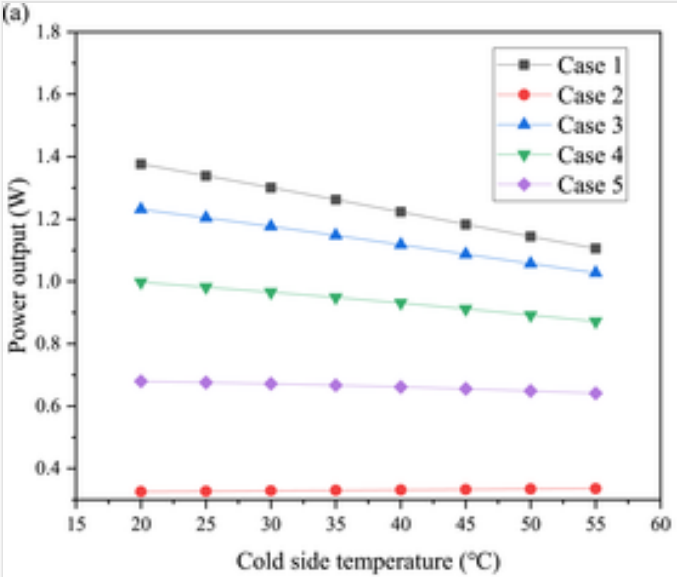

(b)

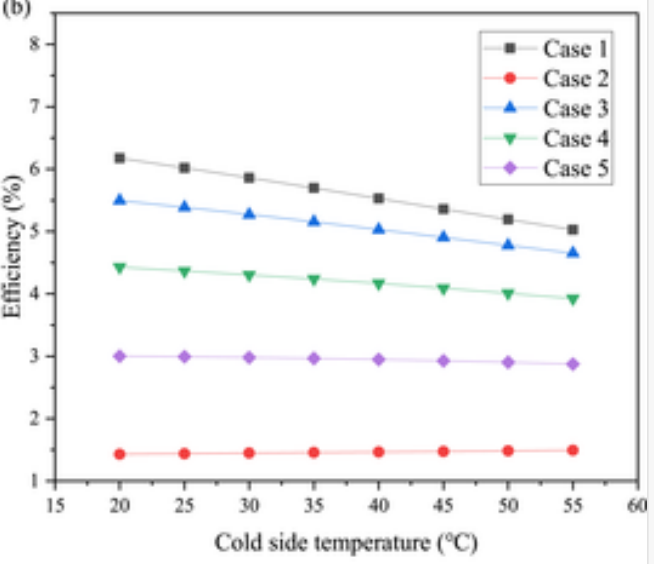

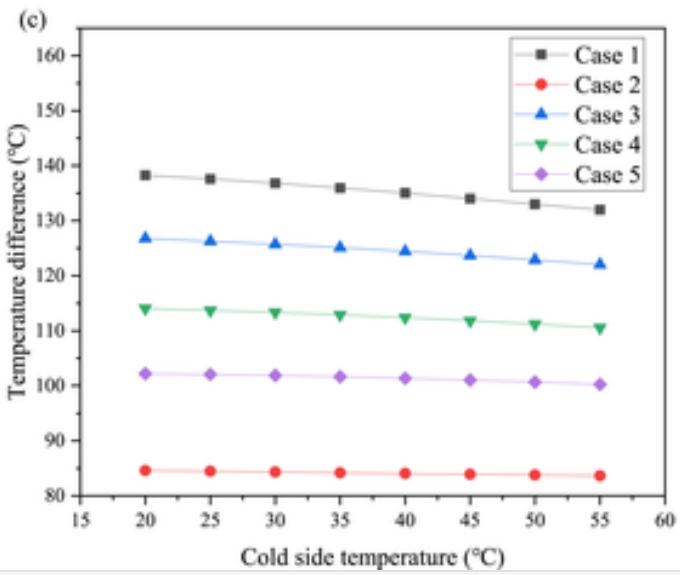

Effect of cold side temperature on (a) power output (b) efficiency and (c) temperature difference.

\subsection{Thermal stress analysis}

Thermal stress is inevitable in a solar thermoelectric generator because of its high operating temperature consequently; this section presents the results from thermal stress analysis. The effect of solar radiation on the maximum von Mises stress in the solar thermoelectric generators is shown in Fig. 9. Firstly, the maximum von 
Mises stress in the thermoelectric legs of all the different design cases is shown in Fig. 9a in addition to the tensile strength of Skutterudite material (142 MPa) and the yielding stress of bismuth telluride material (112 MPa). It is clear that for all solar radiation values, the maximum von Mises stress in the non-segmented solar TEG (Case 1 and Case 2) is lower than that in the segmented solar TEG. Furthermore, it is clear from Fig. 9a that for the segmented solar thermoelectric generator, Case 5 provides the lowest thermal stress in the legs while Case 3 provides the highest thermal stress. As expected, the maximum von Mises stress in the thermoelectric legs for all the cases increase as the solar radiation increase due to the increase in operating temperature. This may lead to a reduction in the service life of the thermoelectric generator or even damage the device. This finding is in agreement with that of Fan et al. [43]. It is also important to note that for the highest solar radiation value considered in this study $\left(21000 \mathrm{~W} / \mathrm{m}^{2}\right)$, the thermal stress in the legs of Skutterudite non-segmented solar TEG (Case 2) is within the acceptable tensile strength of the Skutterudite material, therefore, it can operate safely and reliably at such high solar radiation value. However, for the bismuth telluride non-segmented solar TEG (Case 1), it is clear that the module can only be guaranteed to operate safely and reliably at solar radiation values lower than $15000 \mathrm{~W} / \mathrm{m}^{2}$, beyond which the yielding stress of the material will be exceeded. However, from Fig. 5a, the highest power output of Case 1 was obtained at a radiation value of $13000 \mathrm{~W} / \mathrm{m}^{2}$, thus; if the module is used within its optimum operating temperature, it will provide a reliable and efficient operation in terms of both mechanical and electrical performance. Comparing the segmented design cases, the maximum von Mises stress at a high radiation value of $21000 \mathrm{~W} / \mathrm{m}^{2}$, in Case 5 decrease by $43.58 \%$ and $16.18 \%$ compared to Case 3 and Case 4 respectively. This shows the importance of leg length ratio optimization for thermal stress reduction. The reason for the better mechanical performance of Case 5 is its higher proportion of Skutterudite material compared to Case 3 and Case 4. Skutterudite material provides a better mechanical performance compared to bismuth telluride material however, the reverse is the case in terms of electrical performance. Consequently, it is imperative to optimize solar thermoelectric generators in terms of both electrical and mechanical performance.

alt-text: Fig. 9

Fig. 9 

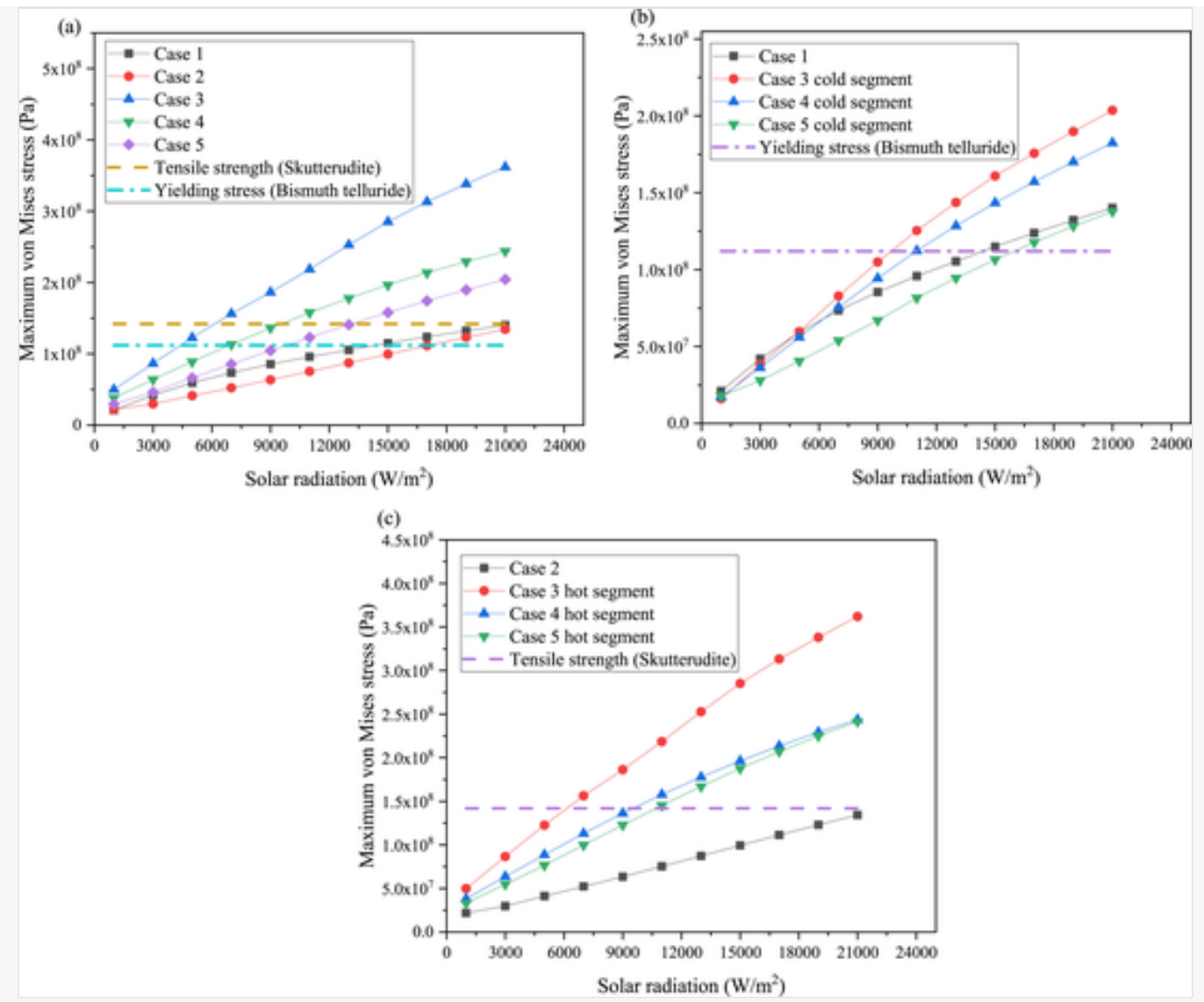

Effect of solar radiation on maximum von Mises stress in (a) different cases (b) bismuth telluride TEG and (b) Skutterudite segment.

Fig. $9 \mathrm{~b}$ provides a better understanding of the maximum von Mises stress in the thermoelectric legs made of bismuth telluride material only. In addition, the advantage of segmentation is shown in this figure. It can be seen clearly that for all solar radiation values considered, the maximum von Mises stress in Case 5 is the lowest, even lower than that in the non-segmented solar TEG (Case 1). For example, at a solar radiation value of $11000 \mathrm{~W} / \mathrm{m}^{2}$, the maximum von Mises stress in the bismuth telluride material (cold segment) of Case 5 decreases by $14.85 \%, 34.93 \%$ and $27.36 \%$ compared to that in Case 1, Case 3 and Case 4 respectively. Furthermore, it can be seen from Fig. $9 \mathrm{~b}$ that Case 3 attains the yielding stress quicker than the remaining cases, followed by Case 4, Case 1 and finally Case 5. This implies that a higher solar radiation value can be used for Case 5 compared to the others within which the module will still be reliable and will provide increased power output. To understand the stress distribution in the legs made of Skutterudite material, Fig. 9c shows the maximum von Mises stress in different cases. It can be seen that Case 2 provides the lowest thermal stress, which is still within the tensile strength of the Skutterudite material even at a high radiation value of $21000 \mathrm{~W} / \mathrm{m}^{2}$. Comparing the segmented solar TEG, it is obvious that Case 5 provides the lowest thermal stress while Case 3 provides the highest thermal stress. A combination of Fig. $9 \mathrm{~b}$ and c gives the results shown in Fig. 9a. The effect of heat flux uniformity on the thermal stress in thermoelectric legs for the different design cases is shown in Fig. 10. It is clear from Fig. 10a-e that the maximum von Mises stress is higher under the uniform heat flux than the non-uniform heat flux. This is simply because of the higher solar energy absorbed 
under uniform heat flux. Although, this is advantageous for power output enhancement, it negatively affects the mechanical reliability of the modules.

alt-text: Fig. 10

Fig. 10
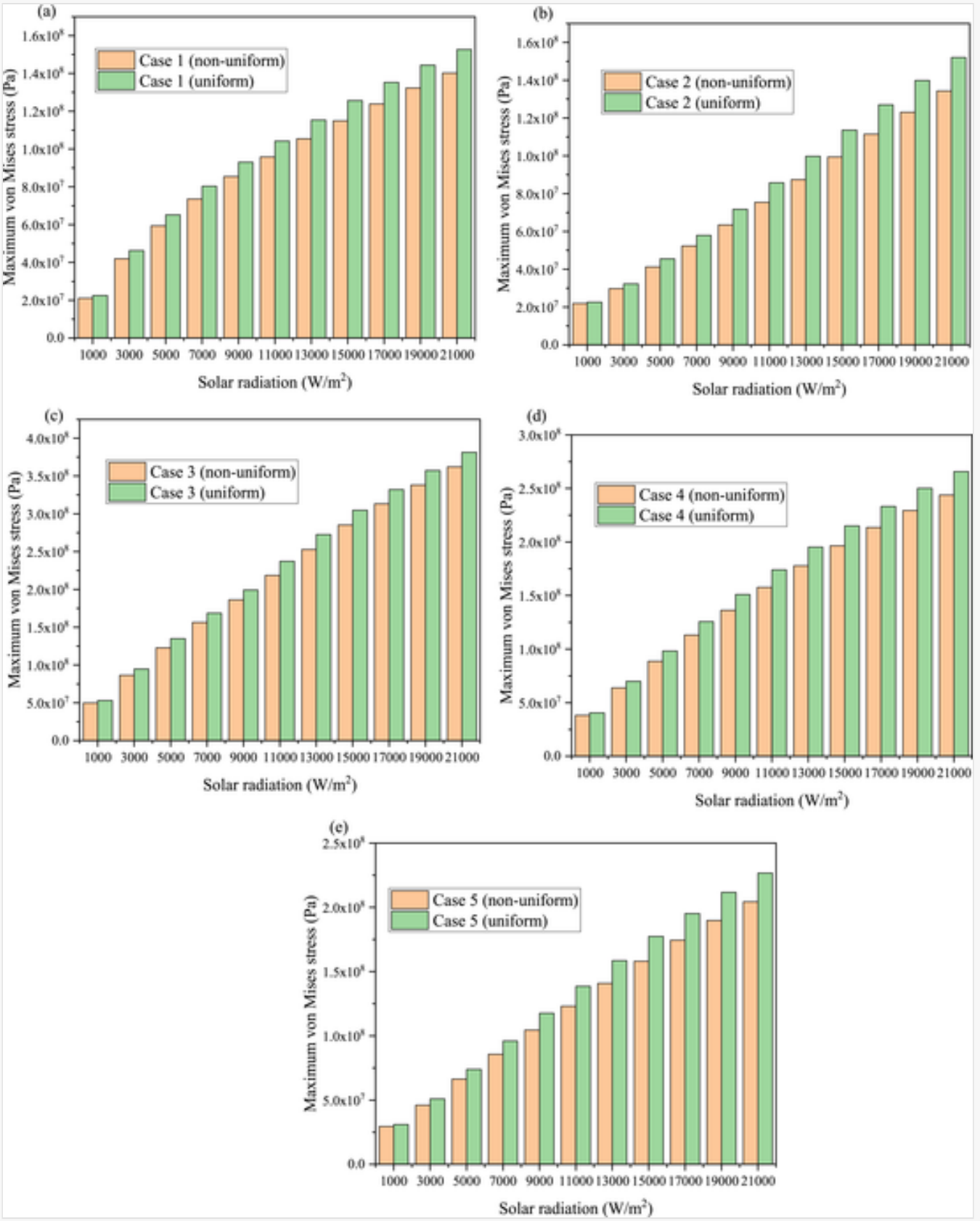

Effect of non-uniform and uniform heat flux on maximum von Mises stress in (a) case 1 (b) case 2 (c) case 3 (d) case 4 and (e) case 5.

\subsection{Three-dimensional distributions}


One of the advantages of this study is that it provides three-dimensional information about the actual temperature and stress distributions in a full-scale solar thermoelectric generator. Fig. 11 shows the temperature distribution of the segmented solar thermoelectric generator (Case 4) under non-uniform and uniform heat flux. It can be seen from Fig. 11a that the maximum temperature in the module is distributed in the middle of the module due to the non-uniformity of the heat flux from the compound parabolic concentrator used. The temperature distribution on the surface of the module shown in Fig. 11a follows the trend of the CPC heat flux shown in Fig. 1c. Furthermore, Fig. 11b shows the temperature distribution under uniform heat flux. It is clear that the temperature is evenly distributed across the surface of the module and the maximum temperature under uniform heat flux is $162{ }^{\circ} \mathrm{C}$ while that under non-uniform heat flux is $148{ }^{\circ} \mathrm{C}$. This difference in temperature is the main reason for the power output improvement observed under uniform heat flux and the reduced mechanical reliability also observed. To properly understand the locations of maximum von Mises stress in the thermoelectric legs of the different design cases, Fig. 12 provides a three-dimensional thermal stress distribution. Fig. 12a-e provide the stress distribution for Case 1, Case 2, Case 3, Case 4 and Case 5 respectively. One obvious trend seen from all the figures is that the maximum von Mises stress all occur at the edge of the thermoelectric legs, thus that region can break off easily. In addition, the other region most likely to crack are the contact areas between the thermoelectric legs hot surface and solder strips. The development of thermal stress in the legs of the solar thermoelectric generator is due to the difference in mechanical material properties of the solar TEG components.

alt-text: Fig. 11

Fig. 11 


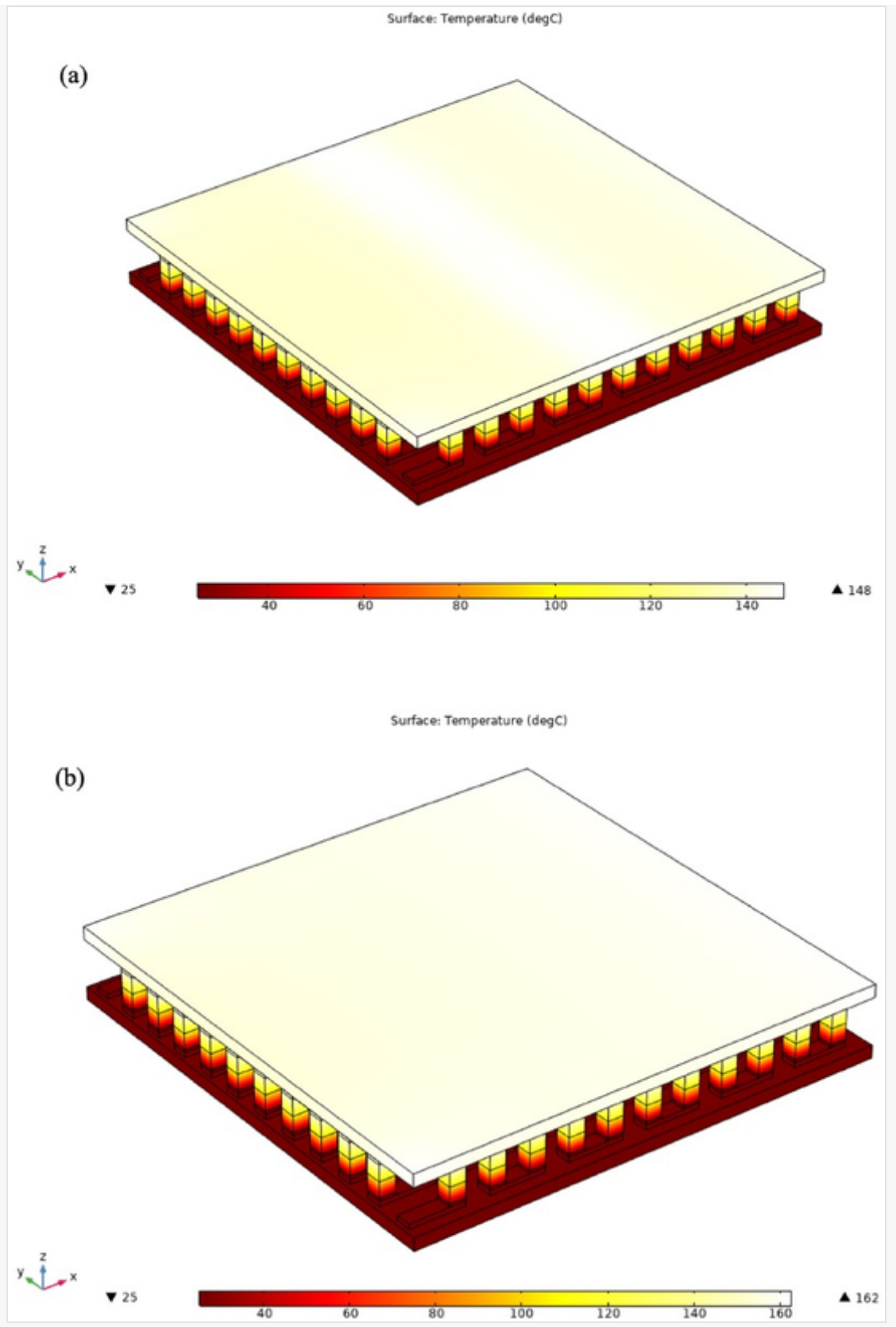

Three-dimensional temperature distribution for (a) non-uniform and (b) uniform heat flux at solar radiation of $5000 \mathrm{~W} / \mathrm{m}^{2}$.

alt-text: Fig. 12 


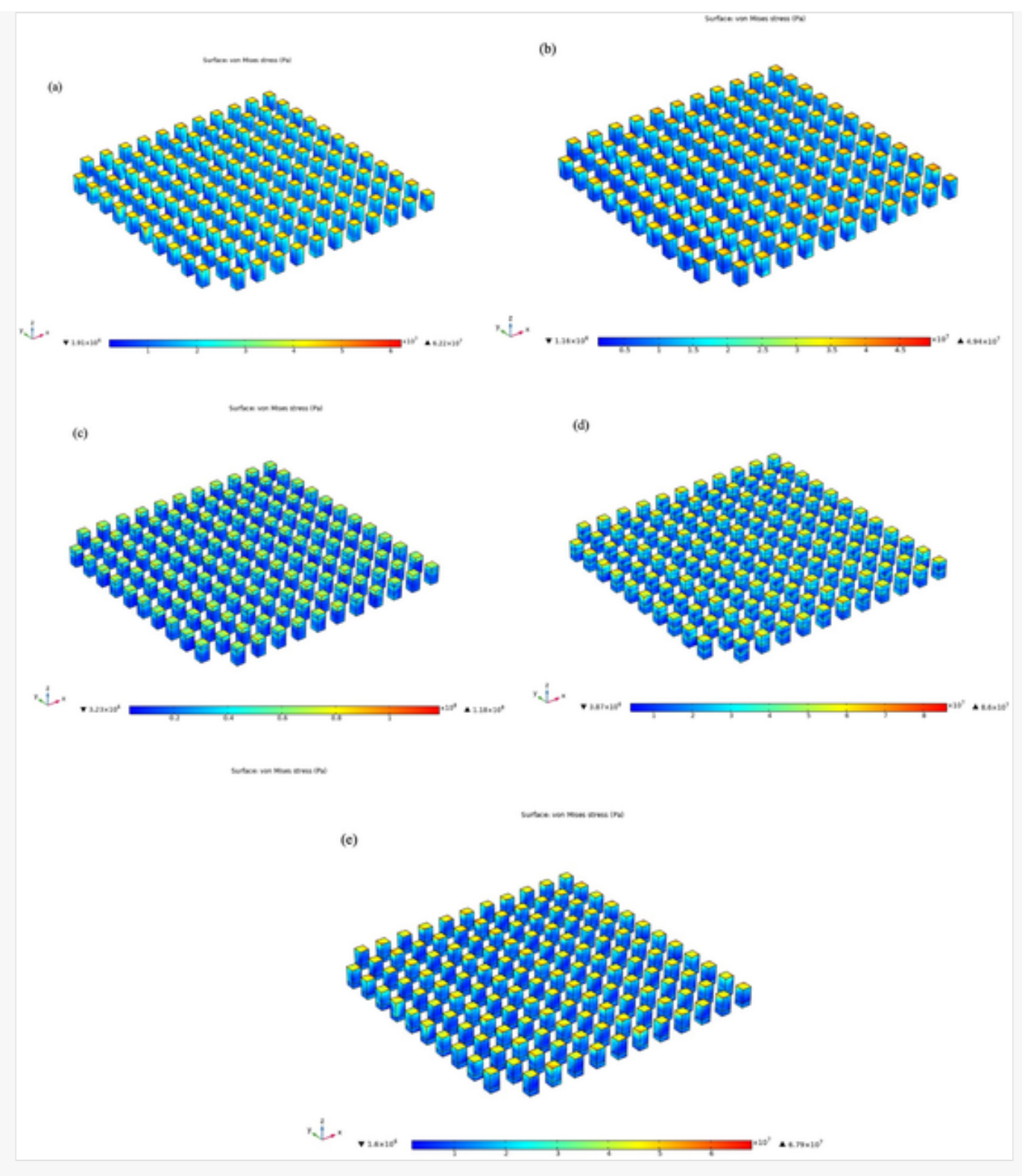

Thermal stress nephogram for (a) case 1 (b) case 2 (c) case 3 (d) case 4 and (e) case 5 at solar radiation of $5000 \mathrm{~W} / \mathrm{m}^{2}$.

\section{Conclusion}

A detailed three-dimensional numerical study on electrical and mechanical performance of segmented and non-segmented solar thermoelectric generator under non-uniform and uniform heat flux was provided in this study. Heat flux from a compound parabolic concentrator (CPC) was obtained using ray tracing in Lighttools software while the numerical study was carried out using COMSOL 5.4 Multiphysics software. A comparison between the effect of non-uniform and uniform heat flux on solar thermoelectric generator performance was provided. In addition, detailed thermal stress analysis was presented for the full-scale solar thermoelectric generator (TEG) simulated and three-dimensional distributions were presented for better understanding. The effects of load resistance, solar radiation and cold side temperature on the performance of solar thermoelectric generator were presented. Five different design cases were studied including two non-segmented solar thermoelectric generator and three segmented solar thermoelectric generator with different leg length ratio. For 
further study, this study can be applied to a real prototype by ensuring the external load resistance is varied until maximum power output is obtained for the specific design case of the thermoelectric generator being considered. Furthermore, geometry optimization should be performed to ensure optimum performance is obtained considering the operating temperature range. In addition, geometry optimization should be implemented to reduce the thermal stress in the thermoelectric legs and thereby increase the life span of the device. The main conclusions from this study are:

1) The optimum load resistance for maximum power output is different for the different design cases considered therefore, the optimum load resistance for the non-segmented case should not be used as reference for the segmented case.

2) The required operating temperature range is a very important parameter which must be considered before choosing an appropriate thermoelectric material and design case.

3) The power output of the segmented solar thermoelectric generators in Case 3, Case 4 and Case 5 increased by $44.07 \%, 59.12 \%$ and $37.9 \%$ respectively compared to that of Case 1 (bismuth telluride non-segmented solar TEG) at $13000 \mathrm{~W} / \mathrm{m}^{2}$.

4) The maximum von Mises stress at a high radiation value of $21000 \mathrm{~W} / \mathrm{m}^{2}$, in Case 5 decreased by $43.58 \%$ and $16.18 \%$ compared to Case 3 and Case 4 respectively thereby showing the importance of leg length ratio optimization in segmented solar TEG.

5) Segmented and non-segmented solar thermoelectric generator must be optimized in terms of both electrical and mechanical performance rather than just electrical performance.

6) At a solar radiation value of $11000 \mathrm{~W} / \mathrm{m}^{2}$, the maximum von Mises stress in the bismuth telluride material (cold segment) of Case 5 decreased by $14.85 \%, 34.93 \%$ and $27.36 \%$ compared to that in Case 1 (non-segmented solar TEG), Case 3 and Case 4 respectively.

\section{CRediT authorship contribution statement}

Samson Shittu: Conceptualization, Software, Validation, Writing - original draft, Writing - review \& editing. Guiqiang Li: Supervision, Project administration. Qindong Xuan: Software, Validation. Xudong Zhao: Funding acquisition. Xiaoli Ma: Supervision. Yu Cui: Visualization.

\section{Declaration of competing interest}

We wish to confirm that there are no known conflicts of interest associated with this publication and there has been no significant financial support for this work that could have influenced its outcome. We confirm that the manuscript has been read and approved by all named authors and that there are no other persons who satisfied the criteria for authorship but are not listed. We further confirm that the order of authors listed in the manuscript has been approved by all of us. We confirm that we have given due consideration to the protection of intellectual property associated with this work and that there are no impediments to publication, including the timing of publication, with respect to intellectual property. In so doing we confirm that we have followed the regulations of our institutions concerning intellectual property. We understand that the Corresponding Author is the sole contact for the Editorial process (including Editorial Manager and direct communications 
with the office). He is responsible for communicating with the other authors about progress, submissions of revisions and final approval of proofs. We confirm that we have provided a current and correct email address which is accessible by the Corresponding Author and which has been configured to accept email from Guiqian g.Li@hull.ac.uk.

\section{Acknowledgement}

This study was sponsored by the Project of EU Marie Curie International incoming Fellowships Program (745614).

\section{Nomenclature}

\begin{tabular}{ll}
\hline$A_{s}:$ & Area of SSA, $\mathrm{m}^{2}$ \\
$\mathrm{C}:$ & Concentration ratio \\
\hline$C_{P}:$ & Specific heat capacity, $\mathrm{J} / \mathrm{kg} / \mathrm{K}$ \\
$\mathrm{E}:$ & Young's modulus, $\mathrm{GPa}$ \\
$\mathrm{G}:$ & Solar radiation, $\mathrm{W} / \mathrm{m}^{2}$ \\
\hline$h:$ & Convective heat transfer coefficient, $W /\left(\mathrm{m}^{2} \cdot \mathrm{K}\right)$ \\
\hline$I:$ & TEG current, A \\
\hline$P_{\text {out }}:$ & TEG Power Output, $\mathrm{W}$ \\
\hline$Q_{\text {in }}:$ & Input power, $\mathrm{W}$ \\
\hline$R_{\text {in }}:$ & Internal resistance, $\Omega$ \\
\hline$R_{L}:$ & Load resistance, $\Omega$ \\
$\mathrm{T}:$ & Temperature, $\mathrm{K}$ \\
\hline$v:$ & Wind speed, $\mathrm{m} / \mathrm{s}$ \\
$V_{L}:$ & Load Voltage, $\mathrm{V}$ \\
\hline$V_{o c}:$ & Open circuit voltage, $\mathrm{V}$ \\
$\mathrm{Z}:$ & Figure of merit, $1 / \mathrm{K}$ \\
\hline
\end{tabular}

\section{Greek symbols}

$\alpha$ :

Seebeck coefficient, V/K

$\alpha_{s}$ :

SSA absorptivity

$\eta_{\text {solarteg: }}$

Solar TEG efficiency, \%

$\sigma:$

Electrical conductivity, $\mathrm{S} / \mathrm{m}$

$\kappa:$

Thermal conductivity, $\mathrm{W} / \mathrm{m} / \mathrm{K}$

$\rho_{d}:$

Density, $\mathrm{Kg} / \mathrm{m}^{3}$

\section{Abbreviations}

$\mathrm{Bi}_{2} \mathrm{Te}_{3}$ :

Bismuth telluride

CPC:

Compound parabolic concentrator

SSA:

Solar selective absorber

STEG:

Segmented thermoelectric generator

TEG:

Thermoelectric generator 


\section{Subscripts}

a:

Ambient

sky:

Sky

\section{References}

(i) The corrections made in this section will be reviewed and approved by a journal production editor. The newly added/removed references and its citations will be reordered and rearranged by the production team.

[1] Shittu S., Li G., Akhlaghi Y.G., Ma X., Zhao X., Ayodele E. Advancements in thermoelectric generators for enhanced hybrid photovoltaic system performance. Renew Sustain Energy Rev 2019;109:24-54. doi:10.1016/j.rser.2019.04.023.

[2] Ma X., Zhao H., Zhao X., Li G., Shittu S. Building integrated thermoelectric air conditioners a potentially fully environmentally friendly solution in building services. Futur Cities Environ 2019;5:1-13. doi:10.5334/fce.76.

[3] Li G., Shittu S., Diallo T.M.O., Yu M., Zhao X., Ji J. A review of solar photovoltaicthermoelectric hybrid system for electricity generation. Energy 2018;158:41-58. doi:10.1016/j.energy.2018.06.021.

[4] Li G., Shittu S., Zhao X., Ma X., zhou K., Zhao X., et al. Preliminary experiment on a novel photovoltaic-thermoelectric system in summer. Energy 2019;188:116041. doi:10.1016/j.energy.2019.116041.

[5] Shittu S., Li G., Zhao X., Zhou J., Ma X. Experimental study and exergy analysis of photovoltaic-thermoelectric with flat plate micro-channel heat pipe. Energy Convers Manag 2020;207:112515. doi:10.1016/j.enconman.2020.112515.

[6] Li G., Ma X., Shittu S., Zhao X. Solar thermoelectric technologies for power generation. In: Zhao X., Ma X., editors. Adv. Energy effic. Technol. Sol. Heating, cool. Power gener.. Cham: Springer International Publishing; 2019. p. 341-371. doi:10.1007/978-3-030-17283-1_10.

[7] Ma H., Yin L., Shen X., Lu W., Sun Y., Zhang Y., et al. Experimental study on heat pipe assisted heat exchanger used for industrial waste heat recovery. Appl Energy 2016;169:177-186. doi:10.1016/j.apenergy.2016.02.012.

[8] Shittu S., Li G., Zhao X., Ma X., Akhlaghi Y.G., Fan Y. Comprehensive study and optimization of concentrated photovoltaic-thermoelectric considering all contact resistances. Energy Convers Manag 2020;205:112422. doi:10.1016/j.enconman.2019.112422.

[9] He W., Wang S., Zhang X., Li Y., Lu C. Optimization design method of thermoelectric generator based on exhaust gas parameters for recovery of engine waste heat. Energy 2015;91:1-9. 
doi:10.1016/j.energy.2015.08.022.

[10] Li G., Zhou K., Song Z., Zhao X., Ji J. Inconsistent phenomenon of thermoelectric load resistance for photovoltaic-thermoelectric module. Energy Convers Manag 2018;161:155-161. doi:10.1016/j.enconman.2018.01.079.

[11] Li G., Zhang G., He W., Ji J., Lv S., Chen X., et al. Performance analysis on a solar concentrating thermoelectric generator using the micro-channel heat pipe array. Energy Convers Manag 2016;112:191-198. doi:10.1016/j.enconman.2016.01.025.

[12] Li G., Ji J., Zhang G., He W., Chen X., Chen H. Performance analysis on a novel micro-channel heat pipe evacuated tube solar collector-incorporated thermoelectric generation. Int J Energy Res 2016;40:2117-2127. doi:10.1002/er.3589.

[13] Rejeb O., Shittu S., Ghenai C., Li G., Zhao X., Bettayeb M. Optimization and performance analysis of a solar concentrated photovoltaic-thermoelectric (CPV-TE ) hybrid system. Renew Energy 2020;152:1342-1353. doi:10.1016/j.renene.2020.02.007.

[14] Ouyang Z., Li D. Modelling of segmented high-performance thermoelectric generators with effects of thermal radiation, electrical and thermal contact resistances. Sci Rep 2016;6:1-12. doi:10.1038/srep24123.

[15] Ali H., Yilbas B.S., Al-Sulaiman F.A. Segmented thermoelectric generator: influence of pin shape configuration on the device performance. Energy 2016;111:439-452. doi:10.1016/j.energy.2016.06.003.

[16] Lundgaard C.C., Sigmund O. Design of segmented off-diagonal thermoelectric generators using topology optimization. Appl Energy 2019;236:950-960. doi:10.1016/j.apenergy.2018.12.021.

[17] Zhang A.B., Wang B.L., Pang D.D., Chen J.B., Wang J., Du J.K. Influence of leg geometry configuration and contact resistance on the performance of annular thermoelectric generators. Energy Convers Manag 2018;166:337-342. doi:10.1016/j.enconman.2018.04.042.

[18] Fan S., Gao Y. Numerical simulation on thermoelectric and mechanical performance of annular thermoelectric generator. Energy 2018;150:38-48. doi:10.1016/j.energy.2018.02.124.

[19] Asaadi S., Khalilarya S., Jafarmadar S. Numerical study on the thermal and electrical performance of an annular thermoelectric generator under pulsed heat power with different types of input functions. Energy Convers Manag 2018;167:102-112. doi:10.1016/j.enconman.2018.04.085.

[20] Li G., Shittu S., Ma X., Zhao X. Comparative analysis of thermoelectric elements optimum geometry between Photovoltaic-thermoelectric and solar thermoelectric. Energy 2019;171:599610. doi:10.1016/j.energy.2019.01.057. 
Fabián-Mijangos A., Min G., Alvarez-Quintana J. Enhanced performance thermoelectric module having asymmetrical legs. Energy Convers Manag 2017;148:1372-1381. doi:10.1016/j.enconman.2017.06.087.

[22] Shi Y., Mei D., Yao Z., Wang Y., Liu H., Chen Z. Nominal power density analysis of thermoelectric pins with non-constant cross sections. Energy Convers Manag 2015;97:1-6. doi:10.1016/j.enconman.2015.02.046.

[23] Karana D.R., Sahoo R.R. Influence of geometric parameter on the performance of a new asymmetrical and segmented thermoelectric generator. Energy 2019;179:90-99. doi:10.1016/j.energy.2019.04.199.

[24] Sun H., Ge Y., Liu W., Liu Z. Geometric optimization of two-stage thermoelectric generator using genetic algorithms and thermodynamic analysis. Energy 2019;171:37-48. doi:10.1016/j.energy.2019.01.003.

[25] Liu Z., Zhu S., Ge Y., Shan F., Zeng L., Liu W. Geometry optimization of two-stage thermoelectric generators using simplified conjugate-gradient method. Appl Energy 2017;190:540-552. doi:10.1016/j.apenergy.2017.01.002.

[26] Liang X., Sun X., Tian H., Shu G., Wang Y., Wang X. Comparison and parameter optimization of a two-stage thermoelectric generator using high temperature exhaust of internal combustion engine. Appl Energy 2014;130:190-199. doi:10.1016/j.apenergy.2014.05.048.

[27] Shittu S., Li G., Zhao X., Ma X. Series of detail comparison and optimization of thermoelectric element geometry considering the PV effect. Renew Energy 2019;130:930-942. doi:10.1016/j.renene.2018.07.002.

[28] Shittu S., Li G., Zhao X., Akhlaghi Y.G., Ma X., Yu M. Comparative study of a concentrated photovoltaic-thermoelectric system with and without flat plate heat pipe. Energy Convers Manag 2019;193:1-14. doi:10.1016/j.enconman.2019.04.055.

[29] Kossyvakis D.N., Vossou C.G., Provatidis C.G., Hristoforou E.V. Computational analysis and performance optimization of a solar thermoelectric generator. Renew Energy 2015;81:150-161. doi:10.1016/j.renene.2015.03.026.

[30] Jung Y.S., Jeong D.H., Kang S.B., Kim F., Jeong M.H., Lee K.S., et al. Wearable solar thermoelectric generator driven by unprecedentedly high temperature difference. Nano Energy 2017;40:663-672. doi:10.1016/j.nanoen.2017.08.061.

[31] Liu L., Lu X., Shi M.L., Ma Y.K., Shi J.Y. Modeling of flat-plate solar thermoelectric generators for space applications. Sol Energy 2016;132:386-394. doi:10.1016/j.solener.2016.03.028.

[32] Lv S., He W., Hu Z., Liu M., Qin M., Shen S., et al. High-performance terrestrial solar thermoelectric generators without optical concentration for residential and commercial rooftops. 
Energy Convers Manag 2019;196:69-76. doi:10.1016/j.enconman.2019.05.089.

[33] Yin E., Li Q., Xuan Y. Effect of non-uniform illumination on performance of solar thermoelectric generators. Front Energy 2018;12:1-10. doi:10.1007/s11708-018-0533-7.

[34] He W., Zhang G., Li G., Ji J. Analysis and discussion on the impact of non-uniform input heat flux on thermoelectric generator array. Energy Convers Manag 2015;98:268-274. doi:10.1016/j.enconman.2015.04.006.

[35] Shittu S., Li G., Zhao X., Ma X., Akhlaghi Y.G., Ayodele E. High performance and thermal stress analysis of a segmented annular thermoelectric generator. Energy Convers Manag 2019;184:180-193. doi:10.1016/j.enconman.2019.01.064.

[36] Snyder G.J. Application of the compatibility factor to the design of segmented and cascaded thermoelectric generators. Appl Phys Lett 2004;84:2436-2438. doi:10.1063/1.1689396.

[37] Zhang G., Fan L., Niu Z., Jiao K., Diao H., Du Q., et al. A comprehensive design method for segmented thermoelectric generator. Energy Convers Manag 2015;106:510-519. doi:10.1016/j.enconman.2015.09.068.

[38] Xiao J., Yang T., Li P., Zhai P., Zhang Q. Thermal design and management for performance optimization of solar thermoelectric generator. Appl Energy 2012;93:33-38. doi:10.1016/j.apenergy.2011.06.006.

[39] Ouyang Z., Li D. Design of segmented high-performance thermoelectric generators with cost in consideration. Appl Energy 2018;221:112-121. doi:10.1016/j.apenergy.2018.03.106.

[40] Liu H.-B.B., Meng J.-H.H., Wang X.-D.D., Chen W.-H.H. A new design of solar thermoelectric generator with combination of segmented materials and asymmetrical legs. Energy Convers Manag 2018;175:11-20. doi:10.1016/j.enconman.2018.08.095.

[41] Ma X., Shu G., Tian H., Xu W., Chen T. Performance assessment of engine exhaust-based segmented thermoelectric generators by length ratio optimization. Appl Energy 2019;248:614625. doi:10.1016/j.apenergy.2019.04.103.

[42] Shittu S., Li G., Zhao X., Ma X., Akhlaghi Y.G., Ayodele E. Optimized high performance thermoelectric generator with combined segmented and asymmetrical legs under pulsed heat input power. J Power Sources 2019;428:53-66. doi:10.1016/j.jpowsour.2019.04.099.

[43] Fan S., Gao Y. Numerical analysis on the segmented annular thermoelectric generator for waste heat recovery. Energy 2019;183:35-47. doi:10.1016/j.energy.2019.06.103.

[44] Ibeagwu O.I. Modelling and comprehensive analysis of TEGs with diverse variable leg geometry. Energy 2019;180:90-106. doi:10.1016/j.energy.2019.05.088. 
Wu Y., Ming T., Li X., Pan T., Peng K., Luo X. Numerical simulations on the temperature gradient and thermal stress of a thermoelectric power generator. Energy Convers Manag 2014;88:915-927. doi:10.1016/j.enconman.2014.08.069.

[46] Jia X., Gao Y. Estimation of thermoelectric and mechanical performances of segmented thermoelectric generators under optimal operating conditions. Appl Therm Eng 2014;73:333340. doi:10.1016/j.applthermaleng.2014.07.069.

[47] Xuan Q., Li G., Pei G., Ji J., Su Y., Zhao B. Optimization design and performance analysis of a novel asymmetric compound parabolic concentrator with rotation angle for building application. Sol Energy 2017;158:808-818. doi:10.1016/j.solener.2017.10.029.

[48] Al-Merbati A.S., Yilbas B.S., Sahin A.Z. Thermodynamics and thermal stress analysis of thermoelectric power generator: influence of pin geometry on device performance. Appl Therm Eng 2013;50:683-692. doi:10.1016/j.applthermaleng.2012.07.021.

[49] Chen L., Lee J. Effect of pulsed heat power on the thermal and electrical performances of a thermoelectric generator. Appl Energy 2015;150:138-149. doi:10.1016/j.apenergy.2015.04.009.

[50] Ming T., Yang W., Wu Y., Xiang Y., Huang X., Cheng J., et al. Numerical analysis on the thermal behavior of a segmented thermoelectric generator. Int J Hydrogen Energy 2017;42:3521-3535. doi:10.1016/j.ijhydene.2016.11.021.

[51] European Thermodynamics Limited GM250-127-14-16 Thermoelectric generator module Datasheet, vols 1-4; 2014.

[52] Yilbas B.S., Akhtar S.S., Sahin A.Z. Thermal and stress analyses in thermoelectric generator with tapered and rectangular pin configurations. Energy 2016;114:52-63. doi:10.1016/j.energy.2016.07.168.

[53] Yin E., Li Q., Xuan Y. Experimental optimization of operating conditions for concentrating photovoltaic-thermoelectric hybrid system. J Power Sources 2019;422:25-32. doi:10.1016/j.jpowsour.2019.03.034.

[54] Gao J.-L., Du Q.-G., Zhang X.-D., Jiang X.-Q. Thermal stress analysis and structure parameter selection for a Bi2Te3-based thermoelectric module. J Electron Mater 2011;40:884-888. doi:10.1007/s11664-011-1611-3.

\section{Highlights}


- Comparison of segmented and non-segmented thermoelectric generator is presented.

- Effect of non-uniform heat flux from a compound parabolic concentrator is studied.

- Three-dimensional numerical study of solar thermoelectric generator is presented.

- Thermal stress analysis on a full-scale thermoelectric generator is performed.

\section{Queries and Answers}

Query: Your article is registered as a regular item and is being processed for inclusion in a regular issue of the journal. If this is NOT correct and your article belongs to a Special Issue/Collection please contact s.venkiteswaran@elsevier.com immediately prior to returning your corrections.

\section{Answer: Yes}

Query: Please confirm that given names and surnames have been identified correctly and are presented in the desired order and please carefully verify the spelling of all authors' names.

Answer: Yes

Query: Please confirm that the provided emails “Guiqiang.Li@hull.ac.uk, Xudong.Zhao@hull.ac.uk” are the correct address for official communication, else provide an alternate e-mail address to replace the existing one, because private e-mail addresses should not be used in articles as the address for communication.

Answer: Yes

Query: Have we correctly interpreted the following funding source(s) you cited in your article: EU Marie Curie International incoming Fellowships Program?

Answer: Yes 